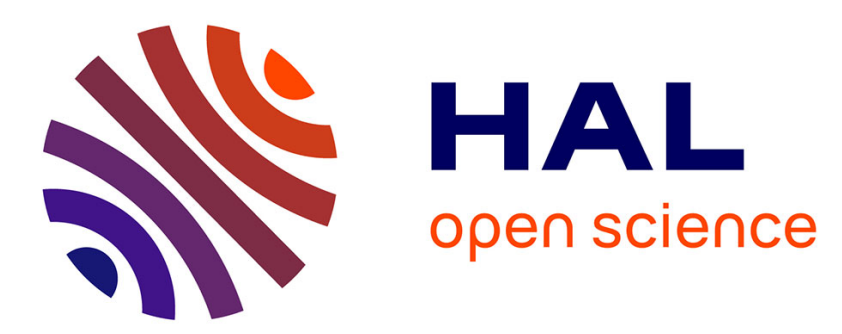

\title{
A practical general method for the preparation of long acenes
}

\author{
Andrej Jancarik, Gaspard Levet, André Gourdon
}

\section{To cite this version:}

Andrej Jancarik, Gaspard Levet, André Gourdon. A practical general method for the preparation of long acenes. Chemistry - A European Journal, In press, 10.1002/chem.201805975 . hal-01961616

\section{HAL Id: hal-01961616 https://hal.science/hal-01961616}

Submitted on 20 Dec 2018

HAL is a multi-disciplinary open access archive for the deposit and dissemination of scientific research documents, whether they are published or not. The documents may come from teaching and research institutions in France or abroad, or from public or private research centers.
L'archive ouverte pluridisciplinaire HAL, est destinée au dépôt et à la diffusion de documents scientifiques de niveau recherche, publiés ou non, émanant des établissements d'enseignement et de recherche français ou étrangers, des laboratoires publics ou privés. 


\title{
A practical general method for the preparation of long acenes
}

\author{
Andrej Jancarik, * Gaspard Levet and André Gourdon*
}

\begin{abstract}
The field of long acenes, the narrowest of the zig-zag graphene nanoribbons, has been an area of significant interest in the past decade due to potential applications in organic electronics, spintronics and plasmonics. However their low solubility and high reactivity has so far hindered their preparation on large scales. We report here a concise strategy for the synthesis of higher acenes through Diels-Alder condensation of arynes with a protected tetraene ketone. After deprotection by cleavage of the ketal, the obtained monoketone precursors cleanly yield the corresponding acenes through quantitative cheletropic thermal decarbonylation in the solid state, at moderate temperatures of 155 to $205^{\circ} \mathrm{C}$. This approach allows the preparation of heptacene, benzo[a]hexacene, cis- and trans-dibenzopentacene and offers a valuable new method for the synthesis of even larger acenes.
\end{abstract}

Acenes are polyaromatic hydrocarbons consisting of linearly fused benzene units and can be considered as the narrowest zig-zag graphene nanoribbons. This topology, with only one Clar aromatic sextet ${ }^{[1]}$ spread over the entire molecule, leads to a decrease of the HOMO-LUMO gap and an increase in the chemical reactivity with increasing number of benzene rings. The nature of electronic structure of long acenes is still actively discussed, in particular the partial contribution of the open-shell singlet state to the electronic ground-state configuration beyond decacene..$^{[2-5]}$ On the other hand, these compounds are predicted to show attractive electronic and magnetic properties. ${ }^{[6]}$ They have been suggested for use as molecular wires in single molecule electronics, for solar-cells applications, ${ }^{[7]}$ for spintronics ${ }^{[8]}$ and plasmonics, ${ }^{[9]}$ as semi-conducting materials ${ }^{[10,11]}$ in organic-field effect transistors ${ }^{[12]}$ and in organic light emitting diodes. ${ }^{[13]}$

To overcome the inherent fragility of long acenes and to improve their solubility and processability, it is possible to attach electron deficient or bulky substituents ${ }^{[14-20]}$ or to introduce heteroatoms into the acene framework like sulfur or nitrogen atoms. ${ }^{[10,14-17,21,22]}$ However, the electronic properties of such materials cannot be compared with their parent acenes.

Since these later are poorly soluble, prone to (photo)oxidation and dimerize in solution, their synthesis remains " a formidable challenge" to quote R. Dorel and A.M. Echavarren. ${ }^{[16]}$ The only way to study them is to prepare more stable, and if possible soluble, precursors that can be converted

\author{
A. Jancarik \\ CEMES-CNR \\ 29 Rue J. Marvig, 31055 Toulouse, France \\ and \\ E-mail : Andrej.jancarik@cemes.fr \\ G. Levet, A. Gourdon \\ CEMES-CNRS \\ 29 Rue J. Marvig, 31055 Toulouse, France \\ E-mail : Andre.gourdon@cemes.fr
}

Institute of Organic Chemistry and Biochemistry of the Czech

Academy of Sciences, 16610 Prague 6, Czech Republic

Supporting information for this article is given via a link at the end of the document in a final step in the solid state through a unimolecular process to the target acenes. This approach has been employed for the synthesis of acenes ${ }^{[23]}$ up to undecacene ${ }^{[24]}$ in low concentration in argon cold matrices, or in $\mathrm{PMMA}^{[25]}$ by photochemical bisdecarbonylation using the Strating-Zwanenburg reaction, ${ }^{[26]}$ and to explore their photophysical properties. ${ }^{[15,27,28]}$ More recently, long acenes have been isolated by on-surface synthesis at lowtemperature metallic surfaces under ultra-high vacuum, through deoxygenation of epoxides, ${ }^{[29-31]}$ dehydrogenation of partially saturated precursors ${ }^{[32,33]}$ and bis-decarbonylation of $\alpha$ diketones. $^{[34,35]}$ These strategies allowed the investigation through scanning tunnelling spectroscopy of the electronic properties $^{[36]}$ of polyacenes up to undecacene and to follow the decrease in energy gap as the number of six-membered rings increases.

In contrast, the preparation in bulk of acenes beyond pentacene has been described only recently. Hexacene has been prepared in 2012 by T.J. Chow et al. ${ }^{[37]}$ by cheletropic thermal decarbonylation of the carbonyl-bridged precursor and heptacene by H.F. Bettinger et al. in $2017^{[38]}$ by thermal cleavage of diheptacene in the solid state, more than 70 years after the first attempted synthesis. Both studies showed that these two long acenes are stable at room temperature, resolving an old controversy and opening new avenues to the preparation of even longer acenes.

We present here a strategy, summarized in the Scheme 1, general enough to prepare a large variety of long acenes beyond pentacene. The starting compound is $(1 \mathrm{~s}, 4 \mathrm{~s})-7,7-$ dimethoxy-2,3,5,6-tetramethylenebicyclo[2.2.1] heptane 1. $^{[39]}$ This tetraene can undergo Diels-Alder cycloaddition with arynes, to give, after aromatization, stable, non-planar and not fully aromatized protected acenes, which after cleavage of the ketals yields the $\mathrm{CO}$ bridged precursors.

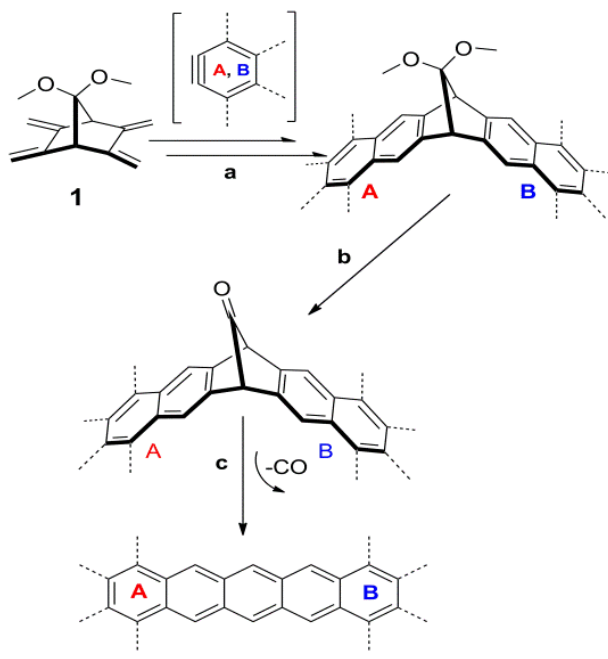

Scheme 1. (a) Diels-Alder reactions of protected tetramethylenebicycloheptanone 1 with ben-zynes in one or two steps. (b) cleavage of the ketal to yield the ketone. (c) heating at ca $190-220^{\circ} \mathrm{C}$ in the solid state yields the corresponding planar acene. 
Quantitative formation of the target acene is then carried out by heating in the solid state at ca $200^{\circ} \mathrm{C}^{[40]}$ with carbon monoxide as the sole by-product. This has allowed preparation, of heptacene 2, dibenzopentacene isomers 3 and $\mathbf{4}$, and benzohexacene $\mathbf{5}$ as representative examples of this method (Figure 1).
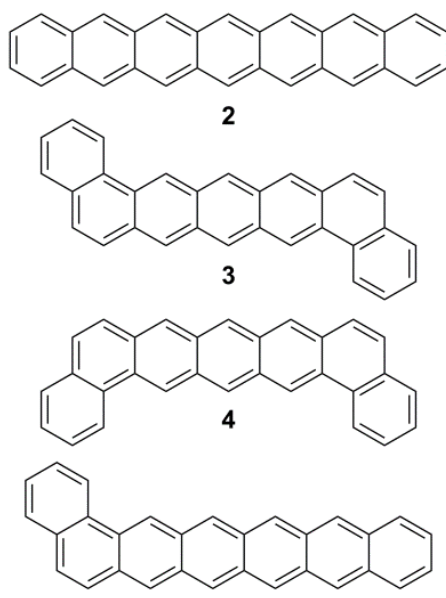

5

Figure 1 Seven-membered ring acenes: 2, heptacene; 3, dibenzo[a,I]pentacene; $\mathbf{4}$, dibenzo[a,n]pentacene; $\mathbf{5}$, benzo[a]hexacene.

\section{1s,4s)-7,7-dimethoxy-2,3,5,6-}

tetramethylenebicyclo[2.2.1] heptane 1. Compound 1 can be obtained from dimethyl fulvene in seven steps as described in ref $^{[39]}$ and we have recently reinvestigated and simplified this synthesis at larger scale, ca tens of grams ${ }^{[41]}$ to obtain $\mathbf{1}$ without any need of purification by chromatography.

Heptacene 2. Heptacene has recently been prepared in bulk, by thermal cleavage of diheptacene by H.F. Bettinger et al., ${ }^{[38]}$ more than seventy years after the first attempted synthesis by Clar. ${ }^{[42]}$ Before this breakthrough, heptacene in stabilizing matrix had been observed by D.C. Neckers et al. ${ }^{[25]}$ through photogeneration from a bridged $\alpha$-diketone using a polymer matrix, and under UHV by on-surface dehydrogenation of the corresponding hydroacene, ${ }^{[32]}$ or using surface-assisted decarbonylation of an $\alpha$-diketone precursor on a $\mathrm{Ag}(111) .{ }^{[34]}$ Using our strategy, we have also obtained heptacene in bulk, which remains so far the longest acene made as pure solid. Diels-Alder addition of $\mathbf{1}$ with two 2,3-naphthyne molecules, prepared in situ by reaction of CsF with 3(trimethylsilyl)naphthalen-2-yl trifluoromethanesulfonate in acetonitrile (route A) or n-butyllithium with 2,3dibromonaphthalene in toluene (route $\mathrm{B}$ ), followed by oxidation with DDQ in toluene, gives 6 in ca $60 \%$ yields. The moderately soluble colourless carbonyl adduct 7 is then obtained by cleavage of the ketal by trimethylsilyl iodide in DCM in 99\% yield.

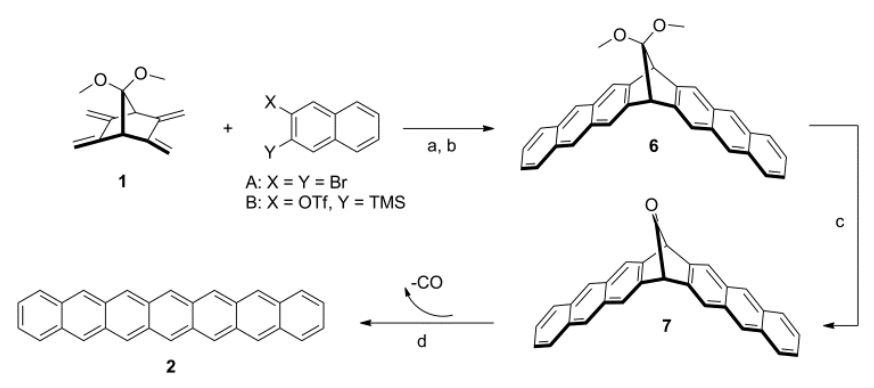

Scheme 2. Synthesis of heptacene 2: (a) A, n-BuLi, toluene. (b) DDQ, toluene $63 \%$. or (a) B, CsF/acetonitrile. (b) DDQ, toluene $60 \%$. (c) TMSI, DCM, $99 \%$. (d) neat, $220^{\circ} \mathrm{C}$, quant

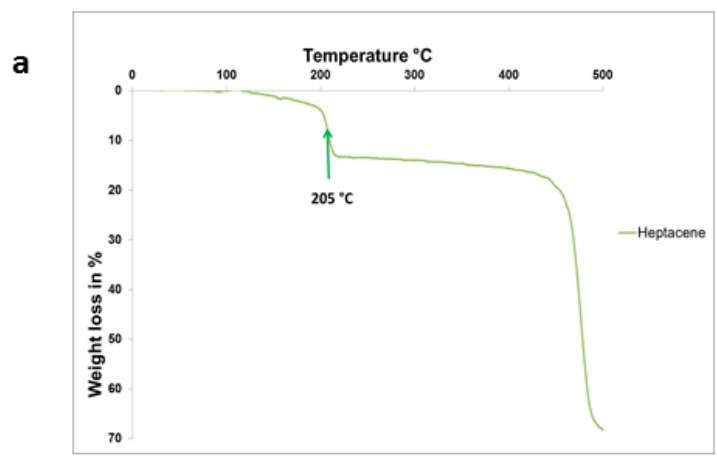

b

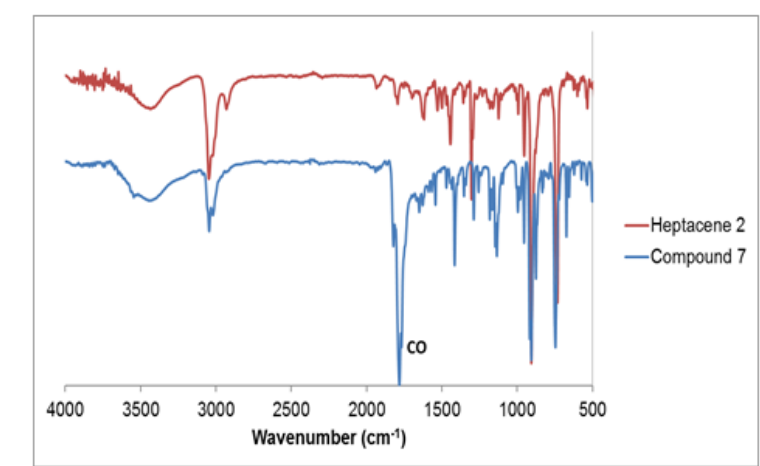

C

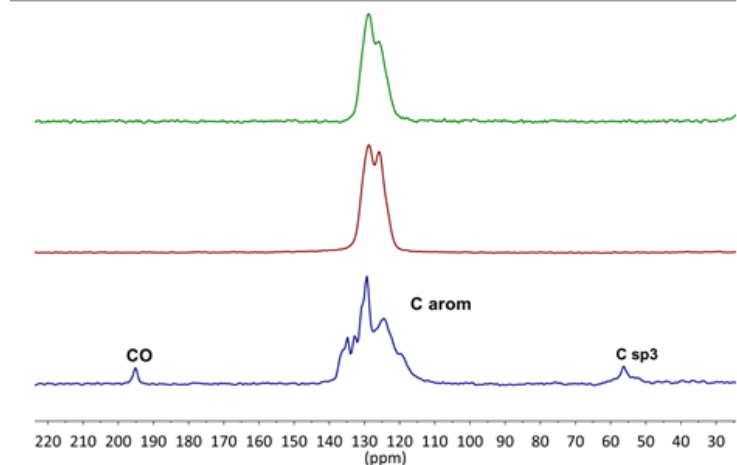

Figure 2. Formation of heptacene 2 by thermal decarbonylation of 7: (a) Thermal Gravimetric Analysis of 7 showing the decar-bonylation at $205^{\circ} \mathrm{C}$ to yield 2. (b) FTIR spectra ( $\mathrm{KBr}$ pellets) of $\mathbf{2}$ and $\mathbf{7}$ showing the disappearance of the $\mathrm{CO}$ peak at $1782 \mathrm{~cm}^{-1}$. (c) Carbon CPMAS spectra of 7 (bottom, blue), 2 (middle, red) just after decarbonylation, and 2 after six weeks at room temperature under argon (top, green). 
The conversion of 7 to heptacene (Figure 2) was followed by thermal gravimetric analysis (Figure 2a). A weight loss of $7.9 \%$ (calcd. $6.9 \%$ ) accompanied by a colour change from white to dark blue, occurred at $205^{\circ} \mathrm{C}$, corresponding to the formation of heptacene by cheletropic $\mathrm{CO}$ extrusion. Under these conditions, heptacene is thermally stable up to $420{ }^{\circ} \mathrm{C}$. The $\mathrm{CO}$ extrusion can also be followed by FTIR with the disappearance of the carbonyl peak of 7 observed at $1782 \mathrm{~cm}^{-1}$ (Figure 2b). This transformation has been also shown by solid state crosspolarization magic angle spinning (CP-MAS) NMR spectroscopy (Figure 2c). The spectrum of the precursor 7 showed three signals, one at $56.3 \mathrm{ppm}$ (bridgehead sp3 carbons), a broad peak at 119-137 ppm (aromatic carbons) and the carbonyl carbon at $195.1 \mathrm{ppm}$. After heating for 15 minutes at $220^{\circ} \mathrm{C}$ in a glove box, the peaks corresponding to bridgehead and carbonyl carbons disappear leaving only a narrower doublet at 125.6 and 129.0 ppm (aromatic carbons). Keeping 2 in a glove-box for six weeks did not lead to any significant change in the spectrum. This is in contrast with results reported for thermally prepared heptacene which progressively dimerized to diheptacene. ${ }^{[38]}$ It is proposed that the packing of our precursor 7 does not favour the dimerization of heptacene $\mathbf{2}$ in the solid state.

Dibenzopentacenes 3 and 4. Dibenzopentacenes (DBPen) have been extensively studied both theoretically and experimentally (in the case of trans-DBPen) for their potential uses in organic electronics. ${ }^{[43]}$ This interest has been renewed by the discovery of superconductivity of trans-DBPen doped with alkali metals with a high critical temperature of $33.1 \mathrm{~K} .{ }^{[4]}$ However these results have never been reproduced and are still controversial. ${ }^{[45,46]}$ One explanation could be that the known synthesis of $\mathbf{3}$ (4 has not yet been described) leads to raw products, requiring multiple train-sublimation purifications ${ }^{[43]}$ so that the exact superconductive phase from raw trans-DBPen remains unknown

Following the route described in Scheme 2 with 1,2naphtyne in place of 2,3-naphthyne, we have obtained dibenzo[a,I]pentacene 3 (trans-DBPen) and dibenzo[a,n]pentacene 4 (cis-DBPen) as shown in Scheme 3. Diels-Alder addition of $\mathbf{1}$ with 1,2-naphthyne, prepared in situ by reaction of 1(trimethylsilyl)naphthalen-2-yl trifluoromethanesulfonate with $\mathrm{CsF}$ in acetonitrile, followed by aromatization using DDQ in refluxing toluene gave a $1: 1$ mixture of isomers $\mathbf{8 a}$ and $\mathbf{8 b}$ in $77 \%$ yield. These two regioisomers can be separated by chiral HPLC giving $\mathbf{8 b}$ and a mixture of the trans-DBPen $\mathbf{8 a}$ diastereoisomers which has not been resolved (see Sup. Mat). The proton NMR of $8 \mathrm{a}$ shows a sp3 singlet at $4.91 \mathrm{ppm}$, integrating for two hydrogens, whereas that of $\mathbf{8 b}$ shows two singlets at 4.85 and $4.96 \mathrm{ppm}$ each integrating for one hydrogen, further indicating their different aromatic conjugation.

Cleavage of the ketal $\mathbf{8 a} / \mathbf{8 b}$ by trimethylsilyl iodide in dichloromethane yielded the stable and soluble DBPen precursors $9 \mathrm{a} / 9 \mathrm{~b}$ respectively in nearly quantitative yields.
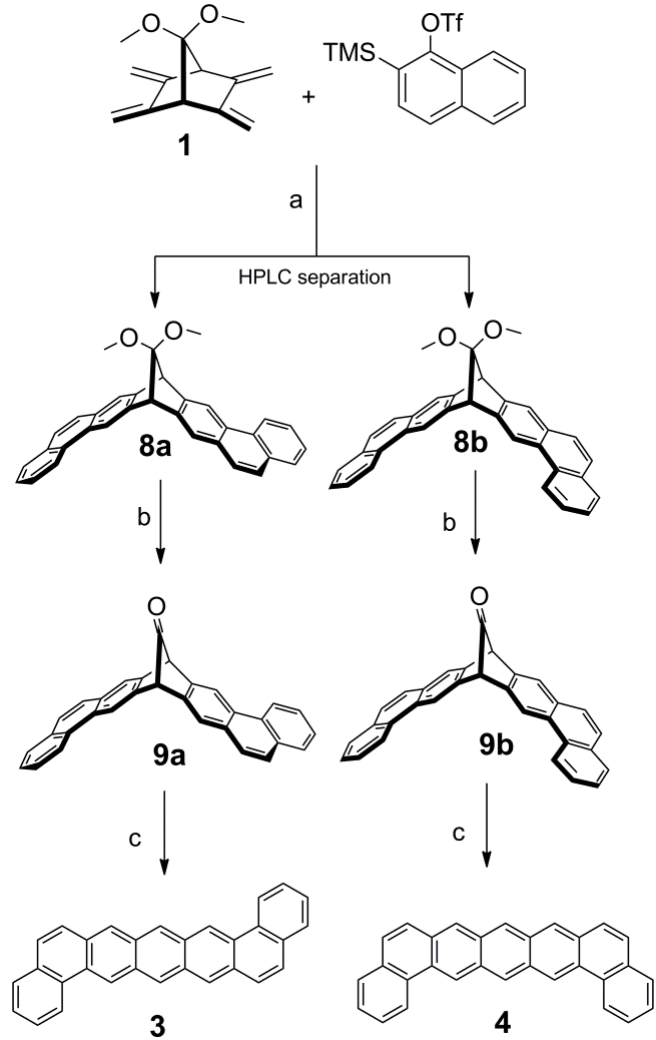

Scheme 3. Preparation of trans 3 and cis-dibenzopentacene 4: (a) CsF acetonitrile, $77 \%$. (b) after separation of isomers: TMSI, DCM, $99 \%$. (c) neat, $200^{\circ} \mathrm{C}$, quant.

The TGA profiles of these precursors (Sup. Mat) exhibit CO expulsion at $185^{\circ} \mathrm{C}$ for $9 \mathrm{a}$ and $155^{\circ} \mathrm{C}$ for $9 \mathrm{~b}$, with corresponding weight losses of $6.4 \%$ and $7.6 \%$ (calcd. $6.9 \%$ ) together with a colour change from white to deep red. Differential thermal analysis (DTA) showed a phase transition at $465^{\circ} \mathrm{C}$ for 3 and at $350{ }^{\circ} \mathrm{C}$ for 4 . Vaporization started for both compounds at ca 320 $350^{\circ} \mathrm{C}$. As in the case of heptacene, the $\mathrm{CO}$ extrusion has been followed by carbon CP-MAS NMR and FTIR in the solid state (see Sup. Mat.). Similarly, the spectra of cis-DBPen $9 b$ showed a C sp3 peak at $55.0 \mathrm{ppm}$, a multiplet between 110 and 140 ppm (C arom.) and a very weak singlet at $191.1 \mathrm{ppm}$ for the CO carbon. For the trans-DBPen isomer $9 a$, peaks are seen at 55.7 ppm (C sp3) and 110-140 ppm (C arom.) with the peak for the carbonyl not apparent. Heating the solid samples for $15 \mathrm{~min}$ in a glove-box at $170{ }^{\circ} \mathrm{C}$ for $9 a$ or $200{ }^{\circ} \mathrm{C}$ for $9 b$ gave the corresponding acenes 3 and $\mathbf{4}$. After $\mathrm{CO}$ extrusion, the solid state 13C NMR spectra shows only one peak at $125.5 \mathrm{ppm}$ for 3 and $125.9 \mathrm{ppm}$ for 4 attributed to the aromatic carbon atoms. Comparison of the infra-red spectra of the carbonyl precursors $9 \mathrm{a}$ and $9 \mathrm{~b}$, before and after decarbonylation shows the loss of carbonyl bands at $1785 \mathrm{~cm}^{-1}(9 \mathbf{a})$ and $1787 \mathrm{~cm}^{-1}(9 \mathbf{b})$ respectively. As DBPen isomers are less prone to dimerization in solution at room temperature, it is possible to carry out this decarbonylation in a high boiling point solvent like 1,1,2,2tetrachloroethane under moderate pressure. The UV-Vis spectra of DBPen isomers were obtained by dissolving the precursors $9 \mathrm{a} / 9 \mathrm{~b}$ and heating at $190^{\circ} \mathrm{C}$ for $15 \mathrm{~min}$ to obtain the compounds 
3 and 4. The spectra were measured at room temperature (Figure 3 and Sup Mat).
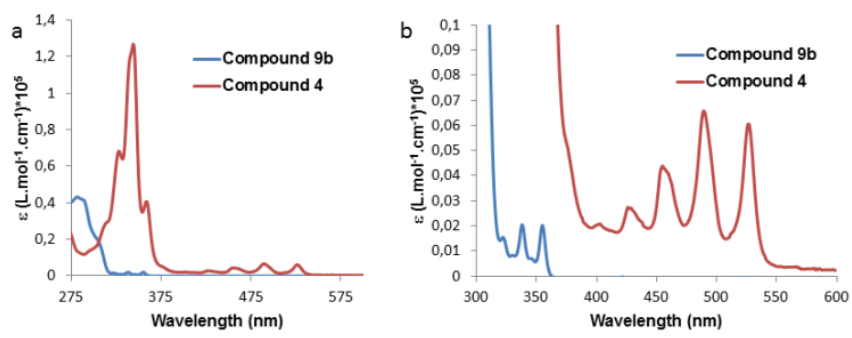

Figure 3. Optical absorption spectra of $9 \mathrm{~b}$ and 4 in 1,1,2,2-tetrachloroethane: (a) Full spectra of the carbonylated precursor $9 \mathrm{~b}$ (blue) and after thermal decarbonylation, 4 (red). (b) zoom of the $p$ band region. Spectra of $9 a$ and 3 are very similar and reported in Sup. Mat.

The $p$ band regions of 3 and $\mathbf{4}$ shows a pattern very similar to that of pentacene with four bands at $427,459,490$ and 527 $\mathrm{nm}$ for 3 (426, 455, 489, $526 \mathrm{~nm}$ for 4), with an hypsochromic shift of $45-65 \mathrm{~nm}$ with respect to pentacene in solution due to the addition of a second aromatic sextet. ${ }^{[47]}$

Benzo[a]hexacene 5. In order to extend the potential of this approach, we have focused on the preparation of asymmetric acenes through reaction of only one diene of the tetraene 1 (Scheme 4).

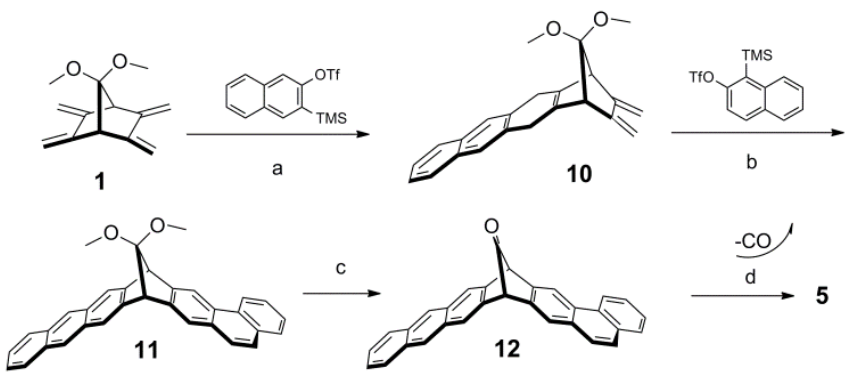

Scheme 4. (a) 3-(trimethylsilyl)naphthalen-2-yl trifluoromethanesulfonate, CsF acetonitrile, $46 \%$. (b) 1-(trimethylsilyl)naphthalen-2-yl

trifluoromethanesulfonate, CsF, acetonitrile; DDQ, toluene, $80 \%$. (c) TMSI,

$\mathrm{DCM}, 96 \%$ (d) neat, $200^{\circ} \mathrm{C}$, quant.

Diels-Alder addition of $\mathbf{1}$ with 1.3 equivalents of 2,3 naphthyne, prepared in situ by reaction of CsF with 3(trimethylsilyl)naphthalen-2-yl trifluoromethanesulfonate in acetonitrile, gave the cis-diene 10 in $46 \%$. This can then be used in other Diels-Alder reactions with arynes, as, for instance, 1,2naphthyne, obtained in situ from 1-(trimethylsilyl)naphthalen-2-yl trifluoromethanesulfonate. After oxidation by DDQ in toluene, $\mathbf{1 1}$ was obtained in $80 \%$ yield as a mixture of two stereoisomers. Cleavage of the later ketal in conditions similar to those used in the preparation of $\mathbf{6}$ and $\mathbf{8}$ provided $\mathbf{1 2}$ in $96 \%$ yield as a white solid. The TGA profiles of 12 showed a CO extrusion at $175^{\circ} \mathrm{C}$ corresponding to a weight loss of $7.2 \%$ (calcd.: $6.9 \%$ ) to give blue benzo[a]hexacene $\mathbf{5}$. As with previous compounds, the formation of 5 in the solid state from its precursor 12 was followed by $13 \mathrm{C}$ CPMAS NMR. At room temperature, the spectrum of 12 shows a peak at $55.7 \mathrm{ppm}$, corresponding to the sp3 carbon, a broad multiplet at 118-136 ppm for the aromatic carbons, and one at $191.7 \mathrm{ppm}$ for the bridging carbonyl group. Decarbonylation at $190{ }^{\circ} \mathrm{C}$ under an argon atmosphere for fifteen minutes gave $\mathbf{5}$, which shows only one single broad CPMAS peak at $125.0 \mathrm{ppm}$. Similarly to the previous acenes, decarbonylation is also demonstrated by disappearance of the CO band at $1785 \mathrm{~cm}^{-1}$ in the IR spectrum of 12 , after heating to yield benzohexacene 5 .

Absorption spectra of thin films. Solid state absorption spectra of thin films of compounds $9 \mathrm{a}, \mathbf{9 b}$ and 12 were obtained by spin-casting on a quartz plate (transparency> $93 \%$ at a wavelength $380 \mathrm{~nm}$ ) from a solution of these compounds in DCM and drying in air. They were then converted to the corresponding acenes $2-4$ by heating at $200^{\circ} \mathrm{C}$ under an argon atmosphere for one minute and the spectra recorded under argon. Due to the low solubility of $\mathbf{7}$ it was not possible to spincast thin layers of this compound. However, optical absorption spectra of thin films of heptacene 2 were obtained recently by H.F. Bettinger by sublimation on sapphire at low temperature $(16 \mathrm{~K}) .{ }^{[38]}$ It was shown that annealing the films to higher temperatures resulted in a decrease of the poorly resolved $\mathrm{p}$ bands. Figure 4 shows the optical absorption spectra of benzo[a]hexacene 5 and its carbonylated precursor 12.

The spectrum of 12 shows three main bands at 401, 379 and $351 \mathrm{~nm}$ attributed to the anthracene parts present in the structure. These features disappear after decarbonylation, with the spectrum of 5 comprising four bands at $609,665,717,770$ $\mathrm{nm}$ with a pattern similar to those of DBPen $\mathbf{3}$ and $\mathbf{4}$ with a bathochromic shift of ca $190 \mathrm{~nm}$ (see Sup. Mat). The thin layer

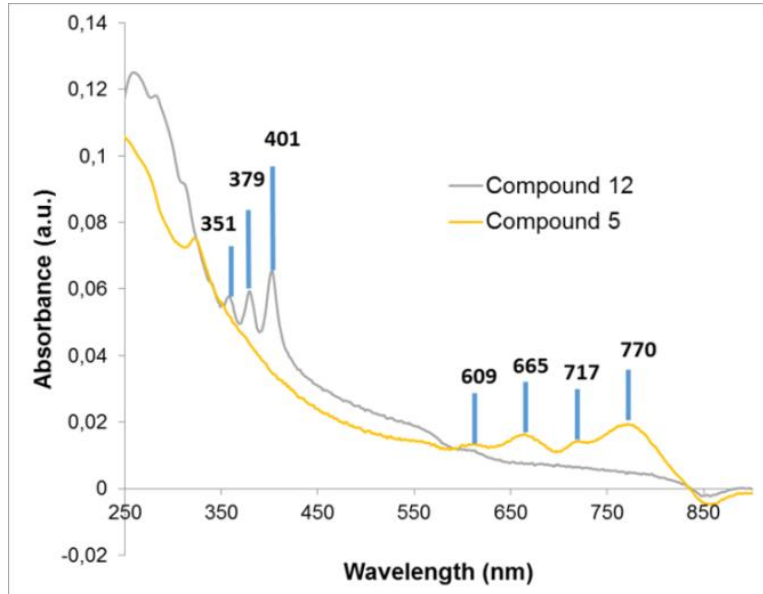

Figure 4 Absorption spectra of thin films: benzo[a]hexacene $\mathbf{5}$ (yellow) and its carbonylated precursor 12 (grey)

spectra of the DBPen isomers $\mathbf{3}$ and $\mathbf{4}$ also show a four bands pattern similar to those observed in solution with a bathochromic shift of $55-60 \mathrm{~nm}$ as expected for thin films versus solution spectra.

To sum up, we describe here a general method allowing for the preparation of pure oligoacenes larger than pentacene, 
despite their chemical and photochemical fragility. The purity and good thermal stability of these compounds will permit the studies of their semiconducting properties for applications including field-effect transistors. Our current work focuses on the semi-preparative scale synthesis of significantly longer linear or branched acenes above heptacene, by successive Diels-Alder reactions from 1 or $\mathbf{1 0}$ with bis-arynes, of donor-acceptor oligoacenes by asymmetric reactions following the strategy developed for the preparation of $\mathbf{5}$

\section{Experimental Section}

General experimental details, synthesis and characterization for all compounds, solution $1 \mathrm{H}$ and $13 \mathrm{C}$ NMR, 13C CPMA, FTIR, and UV-Vis spectra can be found in the Supplementary Information.

\section{Acknowledgements}

The authors thank Yannick Coppel (LCC-Toulouse) for recording CP-MAS spectra, David Neumeyer (CEMES) for recording TGA spectra, Christian Bourgerette (CEMES) and Isabelle Seguy (LAAS) for help in spin-coating experiments. Jiří Rybáček (IOCB Prague) is gratefully acknowledged for the HPLC separation of trans- and cis-DBPen $\mathbf{8 a}$ and $\mathbf{8 b}$. Colin Martin (NAIST-CEMES) is thanked for comments and corrections of the manuscript. A.J. acknowledges funding from the Foundation EXPERIENTIA and from ERDF/ESF "UOCHB MSCA Mobility" (No. CZ.02.2.69/0.0/0.0/17_050/0008490). This research has been funded in parts by the ICT-FET European Union Integrated Project PAMS (Agreement No. 610446) and has received funding from the EraNET Cofund Initiatives QuantERA under the European Union's Horizon 2020 research and innovation programme grant agreement ORQUID. This study has been partially supported through the grant NEXT $n^{\circ}$ ANR-10-LABX0037 in the framework of the "Programme des Investissements d'Avenir".

\section{Keywords • Acenes $\cdot$ Heptacene $\cdot$ Dibenzopentacene $•$} Benzohexacene Alternant hydrocarbons

[1] S. Hauptmann, Z. Für Chem. 2010, 13, 200-200.

[2] Y. Yang, E. R. Davidson, W. Yang, Proc. Natl. Acad. Sci. 2016, 113, E5098.

[3] H. F. Bettinger, C. Tönshoff, M. Doerr, E. Sanchez-Garcia, J. Chem. Theory Comput. 2016, 12, 305-312.

4] H. Chakraborty, A. Shukla, J. Phys. Chem. A 2013, 117, 14220-14229.

[5] S. Horn, F. Plasser, T. Müller, F. Libisch, J. Burgdörfer, H. Lischka, Theor. Chem. Acc. 2014, 133, DOI 10.1007/s00214-014-1511-8.

[6] J.-P. Malrieu, G. Trinquier, J. Phys. Chem. A 2016, 120, 9564-9578.

[7] T. J. Carey, E. G. Miller, A. T. Gilligan, T. Sammakia, N. H. Damrauer, Org Lett. 2018, 20, 457-460.

[8] Z. Sun, Q. Ye, C. Chi, J. Wu, Chem. Soc. Rev. 2012, 41, 7857-7889.
[9] E. B. Guidez, C. M. Aikens, J. Phys. Chem. C 2013, 117, 21466-21475.

[10] C. Wang, H. Dong, W. Hu, Y. Liu, D. Zhu, Chem. Rev. 2012, 112, 2208-2267.

[11] Anthony John E., Angew. Chem. Int. Ed. 2007, 47, 452-483.

[12] A. Naibi Lakshminarayana, A. Ong, C. Chi, J. Mater. Chem. C 2018, 6, 35513563.

[13] J. Li, Y. Zhao, J. Lu, G. Li, J. Zhang, Y. Zhao, X. Sun, Q. Zhang, J. Org. Chem 2015, 80, 109-113.

[14] X. Shi, C. Chi, Chem. Rec. 2016, 16, 1690-1700

[15] C. Tönshoff, H. F. Bettinger, in Polyarenes I (Eds.: J.S. Siegel, Y.-T. Wu), Springer Berlin Heidelberg, Berlin, Heidelberg, 2014, pp. 1-30.

[16] Dorel Ruth, Echavarren Antonio M., Eur. J. Org. Chem. 2016, 2017, 14-24.

[17] K. J. Thorley, J. E. Anthony, Isr. J. Chem. 2014, 54, 642-649.

[18] H. F. Bettinger, C. Tönshoff, Chem. Rec. 2014, 15, 364-369.

[19] B. Purushothaman, S. R. Parkin, J. E. Anthony, Org. Lett. 2010, 12, 2060-2063.

[20] M. M. Payne, S. R. Parkin, J. E. Anthony, J. Am. Chem. Soc. 2005, 127, 80288029.

[21] Zade Sanjio S., Bendikov Michael, Angew. Chem. Int. Ed. 2010, 49, 4012-4015

[22] U. H. F. Bunz, Acc. Chem. Res. 2015, 48, 1676-1686.

[23] H. Yamada, Y. Yamashita, M. Kikuchi, H. Watanabe, T. Okujima, H. Uno, T. Ogawa, K. Ohara, N. Ono, Chem. - Eur. J. 2005, 11, 6212-6220.

[24] B. Shen, J. Tatchen, E. Sanchez-Garcia, H. F. Bettinger, Angew. Chem. Int. Ed. 2018, 57, 10506-10509.

[25] R. Mondal, B. K. Shah, D. C. Neckers, J. Am. Chem. Soc. 2006, 128, 9612 9613.

[26] J. Strating, B. Zwanenburg, A. Wagenaar, A. C. Udding, Tetrahedron Lett. 1969, 10, 125-128.

[27] R. Mondal, C. Tönshoff, D. Khon, D. C. Neckers, H. F. Bettinger, J. Am. Chem Soc. 2009, 131, 14281-14289.

[28] H. F. Bettinger, R. Mondal, D. C. Neckers, Chem. Commun. 2007, 5209-5211.

[29] N. Pavliček, P. Gawel, D. R. Kohn, Z. Majzik, Y. Xiong, G. Meyer, H. L. Anderson, L. Gross, Nat. Chem. 2018, 10, 853-858

[30] J. Krüger, F. Eisenhut, J. M. Alonso, T. Lehmann, E. Guitián, D. Pérez, D. Skidin, F. Gamaleja, D. A. Ryndyk, C. Joachim, et al., Chem. Commun. 2017, $53,1583-1586$.

[31] Krüger Justus, García Fátima, Eisenhut Frank, Skidin Dmitry, Alonso José M., Guitián Enrique, Pérez Dolores, Cuniberti Gianaurelio, Moresco Francesca, Peña Diego, Angew. Chem. 2017, 129, 12107-12110.

[32] R. Zuzak, R. Dorel, M. Krawiec, B. Such, M. Kolmer, M. Szymonski, A. M. Echavarren, S. Godlewski, ACS Nano 2017, 11, 9321-9329.

[33] R. Zuzak, R. Dorel, M. Kolmer, M. Szymonski, S. Godlewski, A. M. Echavarren, Angew. Chem. Int. Ed. 2018, 57, 10500-10505.

[34] M. Zugermeier, M. Gruber, M. Schmid, B. P. Klein, L. Ruppenthal, P. Muller, R. Einholz, W. Hieringer, R. Berndt, H. F. Bettinger, et al., Nanoscale 2017, 9 , 12461-12469.

[35] J. I. Urgel, H. Hayashi, M. Di Giovannantonio, C. A. Pignedoli, S. Mishra, O. Deniz, M. Yamashita, T. Dienel, P. Ruffieux, H. Yamada, et al., J. Am. Chem. Soc. 2017, 139, 11658-11661.

[36] J. Krüger, F. Eisenhut, D. Skidin, T. Lehmann, D. A. Ryndyk, G. Cuniberti, F. García, J. M. Alonso, E. Guitián, D. Pérez, et al., ACS Nano 2018, DOI 10.1021/acsnano.8b04046.

[37] M. Watanabe, Y. J. Chang, S.-W. Liu, T.-H. Chao, K. Goto, IslamMd. Minarul, C.-H. Yuan, Y.-T. Tao, T. Shinmyozu, T. J. Chow, Nat Chem 2012, 4, 574-578.

[38] R. Einholz, T. Fang, R. Berger, P. Grüninger, A. Früh, T. Chassé, R. F. Fink, H. F. Bettinger, J. Am. Chem. Soc. 2017, 139, 4435-4442.

[39] Roth Wolfgang R., Langer Reinhard, Ebbrecht Thomas, Beitat Arndt, Lennartz Hans-Werner, Chem. Ber. 1991, 124, 2751-2760.

[40] M. Watanabe, K.-Y. Chen, Y. J. Chang, T. J. Chow, Acc. Chem. Res. 2013, 46, $1606-1615$

[41] A. Jancarik, G. Levet, Nguyen-Kahn, Hung, Gourdon, Andre, et al., 2018

[42] E. Clar, Berichte Dtsch. Chem. Ges. B Ser. 1942, 75, 1330-1338.

[43] F. Otto, T. Huempfner, M. Schaal, C. Udhardt, L. Vorbrink, B. Schroeter, R. Forker, T. Fritz, J. Phys. Chem. C 2018, 122, 8348-8355.

[44] M. Xue, T. Cao, D. Wang, Y. Wu, H. Yang, X. Dong, J. He, F. Li, G. F. Chen, Sci. Rep. 2012, 2, 389.

[45] S. Heguri, M. Kobayashi, K. Tanigaki, Phys. Rev. B 2015, 92, DOI 10.1103/PhysRevB.92.014502.

[46] F. Roth, A. König, B. Mahns, B. Büchner, M. Knupfer, Eur. Phys. J. B 2012 $85,242$.

[47] Clar E., in Mob. Source Emiss. Policyclic Org. Species, D. Rondia, M. Cooke, R.K. Haroz, 2012, pp. 49-58.

\section{Conflicts of interest}

The authors declare no conflict of interest 

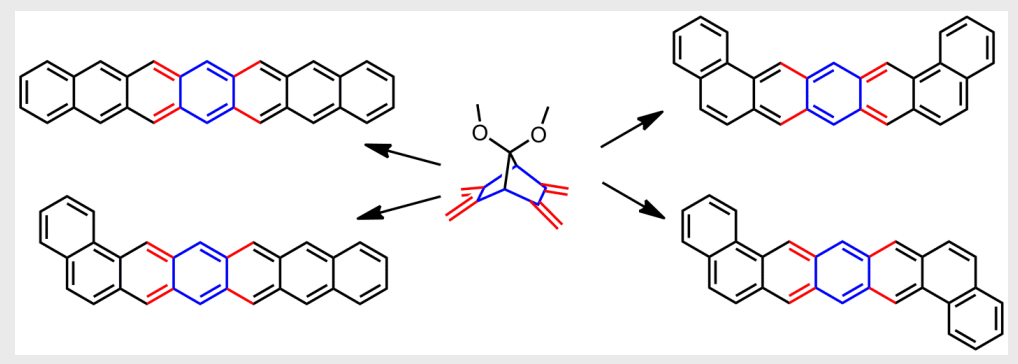

Andrej Jancarik, * Gaspard Levet and André Gourdon*

Page No. - Page No.

A practical general method for the preparation of long acenes

Symmetrical and non-symmetrical chemically fragile and poorly soluble acenes beyond pentacene can be obtained from a protected bicyclic tetraene. The method involves Diels-Alder addition with arynes, oxidation and cleavage of the ketal to give a soluble and stable polyaromatic ketone. Solid state cheletropic decarbonylation gives the targeted oligoacene in quantitative yield. 


\title{
ORCID
}

\author{
Andrej Jancarik : $\quad$ 0000-0002-6944-1002 \\ Gaspar Levet : $\quad$ 0000-0002-1478-0736 \\ André Gourdon : $\quad$ 0000-0002-0370-1019
}

\section{Table of Contents}

\author{
S1. Experimental procedures \\ S2. $1 \mathrm{H}$ and $13 \mathrm{C}$ spectra \\ S3 Infrared spectra \\ S4 TG-DTA of $9 a / 3,9 b / 4$ and 12/5 \\ S5. UV/Vis spectra
}

\section{S1 Experimental Procedures}

\section{General information}

Starting compounds, catalysts and solvents were purchased from Sigma-Aldrich and TCl. Flash column chromatography was performed by using silica gel ( $60 \AA \AA$ pore size, $40-63 \mu \mathrm{m}$ Merck). The reactions were monitored by thin layer chromatography (TLC) on silica gel-coated plates (Merck $60 \mathrm{~F}_{254}$ ). The NMR spectroscopic data in solution were recorded with Bruker Avance $300 \mathrm{MHz}$ and $500 \mathrm{MHz}$ instruments and were calibrated by using the residual undeuterated solvent as an internal reference $\left(\mathrm{CD}_{2} \mathrm{Cl}_{2}\right.$ at $\delta \mathrm{H}=5.33$ $\mathrm{ppm}, \delta \mathrm{C}=53.84 \mathrm{ppm} ; \mathrm{CDCl}_{3}$ at $\delta \mathrm{H}=7.26 \mathrm{ppm}, \delta \mathrm{C}=77.16 \mathrm{ppm}$; tetrachloroethane $-\mathrm{d}_{2}$ at $\delta \mathrm{H}=6.00 \mathrm{ppm}, \delta \mathrm{C}=73.78 \mathrm{ppm}$ ). Chemical shifts are reported in parts per million (ppm) on the $\delta$ scale and coupling constants $(\mathrm{J})$ are in Hertz (Hz). The abbreviations used to describe the multiplicities are $s=$ singlet, $d d=$ doublet of doublets $d d d=$ doublet of doublet of doublet. Mass spectra were recorded at the Service Commun de Spectrometrie de Masse of University Paul Sabatier (Toulouse 3), Toulouse (France) and CP MAS NMR were recorded at the Laboratoire de Chimie de Coordination on a Bruker Avance IIIHD 400 spectrometer equipped with a $2.5 \mathrm{~mm}$ probe. Samples were spun at $14 \mathrm{kHz}$ at the magic angle using $\mathrm{ZrO}_{2}$ rotors. ${ }^{13} \mathrm{C}-\mathrm{CP} / \mathrm{MAS}$ were recorded with a recycle delay of $1.5 \mathrm{~s}$ and a contact time of $3 \mathrm{~ms}$. All chemical shifts for ${ }^{13} \mathrm{C}$ are relative to TMS. Thermal analyses (TG/DSC) were carried out on a Setaram Labsys instrument under flowing helium $\left(45 \mathrm{~mL} \mathrm{~min}{ }^{-1}\right)$ with the heating rate of $10^{\circ} \mathrm{C} \mathrm{min}^{-1}$ from $30{ }^{\circ} \mathrm{C}$ to $550{ }^{\circ} \mathrm{C}$. The samples $(5 \mathrm{mg}$ ) were contained in $100 \mu \mathrm{L}$ aluminum crucibles. IR spectra were measured on a PerkinElmer Spectrum $100 \mathrm{FT}-\mathrm{IR}$ spectrometer with samples as KBr pellets. UV - Vis spectra were recorded on a Varian Cary 5000 spectrophotometer.

\section{Absorption spectra of thin films and in solution}

Solid state absorption spectra of compounds $9 \mathbf{a} / \mathbf{9 b}, 12$ were obtained by spin-coating on a quartz plate ( $1 \mathrm{~mm}$ thickness, transparency $>93 \%$ at a wavelength $380 \mathrm{~nm})$. A solution with maximum concentration $(1 \mathrm{mg} / \mathrm{mL}$ for $9 \mathrm{a}, 0.25 \mathrm{mg} / \mathrm{mL}$ for $9 \mathrm{~b}, 0.6$ $\mathrm{mg} / \mathrm{mL}$ for 12) of each compound in dichloromethane was spincasted at $500 \mathrm{rpm}$ for $30 \mathrm{~s}$. The glass plates were installed diagonally inside a $1 \times 1 \mathrm{~cm}$ quartz cuvette. All these compounds were converted to the corresponding acenes 3-5 by heating at $200{ }^{\circ} \mathrm{C}$ for $1 \mathrm{~min}$ under an argon atmosphere and recorded under argon by keeping the glass plate inside a $1 \times 1 \mathrm{~cm}$ quartz cuvette. The UV - Vis spectra for $\mathbf{7}$ and $\mathbf{2}$ were not measured due to high insolubility. The absorption spectra in solution were made by dissolving compound $9 \mathrm{a}(1.63 \mathrm{mg})$ and $9 \mathrm{~b}(1.14 \mathrm{mg})$ in 1,1,2,2-tetrachloroethane $(200 \mathrm{~mL})$ and measured in $1 \times 1 \mathrm{~cm}$ quartz cuvette. These solutions of $9 \mathrm{a}$ and $\mathbf{9 b}$ were precisely degassed in an Young tube and then heated at $190{ }^{\circ} \mathrm{C}$ for 15 min to produce $\mathbf{3}$ and $\mathbf{4}$. The formed solutions of $\mathbf{3}$ and $\mathbf{4}$ were cooled to room temperature and in a glovebox transferred to a $1 \times 1 \mathrm{~cm}$ quartz cuvettes.

\section{Thermal Gravimetric Analysis}

Ca 3-5 mg of samples were precisely weighed in a $100 \mu$ alumina crucible and placed into a Setaram Labsys device. Before analysis, sample and analysis chamber were purged first in vacuo and then by flowing helium $(45 \mathrm{ml} / \mathrm{min})$ during 8 hours. The absence of oxygen was checked with a lambda analyzer (Setnag JC15V) coupled with the Labsys device. Dual thermogravimetry (TG) and differential thermal analysis (DTA) of samples were made simultaneously using a ramp rate of $10^{\circ} \mathrm{C} / \mathrm{min}$, from $30^{\circ} \mathrm{C}$ to $550{ }^{\circ} \mathrm{C}$ and with a helium flow of $45 \mathrm{ml} / \mathrm{min}$. 


\section{S2 Peak attribution in NMR spectra}

19,19-dimethoxy-7,16-dihydro-7,16-methanoheptacene (6)<smiles>COC(OC)(OC)c1cc2cc3ccccc3cc2cc1I</smiles>

${ }^{1} \mathrm{H}$ NMR $\left(300 \mathrm{MHz}, \mathrm{CDCl}_{3}\right): 3.30(6 \mathrm{H}, \mathrm{s}, \mathrm{H10}), 4.47(2 \mathrm{H}, \mathrm{s}, \mathrm{H1}), 7.39-7.42(4 \mathrm{H}, \mathrm{m}, \mathrm{H} 8), 7.87(4 \mathrm{H}, \mathrm{s}, H 3), 7.91-7.94(4 \mathrm{H}, \mathrm{m}, \mathrm{H} 7)$, $8.27(4 \mathrm{H}, \mathrm{s}, \mathrm{H} 5)$.

${ }^{13} \mathrm{C}$ NMR (126 MHz, $\left.\mathrm{CDCl}_{3}\right): 51.44$ (C10), 54.74 (C1), 120.28 (C3), 123.39 (C9), 125.17 (C8), 126.07 (C5), 128.08 (C7), 131.37 (C4), $131.67(C 6), 142.19(C 2)$.

\section{7,16-dihydro-7,16-methanoheptacen-19-one (7)}<smiles>O=C1C2=Cc3cc4ccccc4cc3C2c2cc3cc4ccccc4cc3cc21</smiles>

${ }^{1} \mathrm{H}$ NMR $\left(500 \mathrm{MHz}\right.$, tetrachloroethane- $\left.d_{2}, 80^{\circ} \mathrm{C}\right): 5.01(2 \mathrm{H}, \mathrm{s}), 7.49(4 \mathrm{H}, \mathrm{dd}, J=6.5,3.1), 8.01(4 \mathrm{H}, \mathrm{dd}, J=6.5,3.3), 8.10(4 \mathrm{H}, \mathrm{s}), 8.42$ $(4 \mathrm{H}, \mathrm{s})$.

${ }^{13} \mathrm{C}$ NMR (126 MHz, tetrachloroethane- $d_{2}$ ): Not recorded due to the low solubility.

\section{9,19-dimethoxy-8,17-dihydro-8,17-methanodibenzo[a,I]pentacene (8a)}<smiles></smiles>

${ }^{1} \mathrm{H}$ NMR $\left(500 \mathrm{MHz}, \mathrm{CD}_{2} \mathrm{Cl}_{2}\right): 3.28(6 \mathrm{H}, \mathrm{s}, H 17), 4.91(2 \mathrm{H}, \mathrm{s}, H 1), 7.56(2 \mathrm{H}, \mathrm{ddd}, J=8.0,6.9,1.2, H 14), 7.64(2 \mathrm{H}, \mathrm{ddd}, J=8.4,6.9,1.4$, H13), 7.67 - $7.72\left(4 \mathrm{H}, \mathrm{ABq}, \mathrm{J}_{\mathrm{AB}}=9.4, H 10, H 11\right), 7.86(2 \mathrm{H}, \mathrm{dd}, J=7.8,1.4, H 15), 7.86(2 \mathrm{H}, \mathrm{s}, H 7), 8.66(2 \mathrm{H}, \mathrm{d}, J=8.0, H 12), 8.67$ $(2 \mathrm{H}, \mathrm{s}, \mathrm{H4})$.

${ }^{13} \mathrm{C}$ NMR (126 MHz, $\left.\mathrm{CD}_{2} \mathrm{Cl}_{2}\right): 51.67$ (C17), 56.03 (C1), 116.53 (C4), 122.21 (C7), 123.09 (C12), 126.64 (C14), 126.87 (C11), 126.88 (C16), 126.89 (C13), 127.44 (C10),129.00 (C15), 129.24 (C5), 130.86 (C8), 131.23 (C6), 132.59 (C9), 145.10 (C3), 145.24 (C2).

\section{9,19-dimethoxy-8,17-dihydro-8,17-methanodibenzo[a,n]pentacene (8b)}

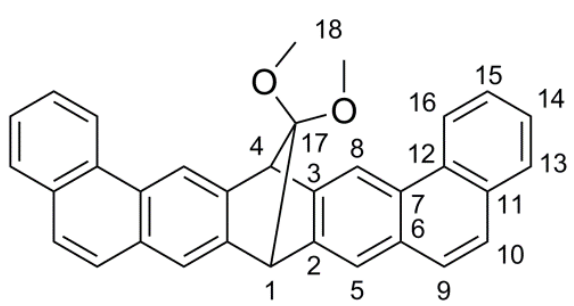

8b 
${ }^{1} \mathrm{H}$ NMR $\left(500 \mathrm{MHz}, \mathrm{CD}_{2} \mathrm{Cl}_{2}\right): 3.27(6 \mathrm{H}, \mathrm{s}, H 18), 4.85(1 \mathrm{H}, \mathrm{d}, J=1.5, H 1), 4.96(1 \mathrm{H}, \mathrm{d}, J=1.5, H 4), 7.55(2 \mathrm{H}, \mathrm{ddd}, J=8.1,7.0,1.2$, H14), $7.64(2 \mathrm{H}, \mathrm{ddd}, J=8.4,6.9,1.4, H 15), 7.69(2 \mathrm{H}, \mathrm{d}, J=8.95, H 9), 7.71(2 \mathrm{H}, \mathrm{d}, J=8.95, H 10) 7.84(2 \mathrm{H}, \mathrm{s}, H 5), 7.86(2 \mathrm{H}, \mathrm{dd}, J=$ $7.9,1.4, H 13), 8.67(2 \mathrm{H}, \mathrm{dd}, J=8.5,1.1, H 16), 8.68(2 \mathrm{H}, \mathrm{s}, H 8)$.

${ }^{13} \mathrm{C}$ NMR (126 MHz, $\left.\mathrm{CD}_{2} \mathrm{Cl}_{2}\right): 51.67$ (C18), 55.59 (C1), 56.47 (C4), 116.55 (C8), 122.19 (C5), 123.08 (C16), 126.64 (C14), 126.86 (C10), 126.87(C17), 126.89 (C15), 127.43 (C9), 128.99 (C13), 129.25 (C7), 130.85 (C12), 131.22 (C6), 132.59 (C11), 145.01 (C2), $145.33(\mathrm{C} 3)$.

\section{8,17-dihydro-8,17-methanodibenzo[a,I]pentacen-19-one (9a)}<smiles>O=C1c2cc3ccc4ccccc4c3cc2C2CC1c1cc3ccccc3cc12</smiles>

${ }^{1} \mathrm{H}$ NMR $\left(500 \mathrm{MHz}\right.$, tetrachloroethane- $\left.d_{2}\right): 5.27(2 \mathrm{H}, \mathrm{s}), 7.62(2 \mathrm{H}, \mathrm{ddd}, J=7.9,6.9,1.1), 7.69(2 \mathrm{H}, \mathrm{ddd}, J=8.4,7.0,1.4), 7.74(2 \mathrm{H}, \mathrm{d}$, $J=9.0), 7.76(2 \mathrm{H}, \mathrm{d}, J=9.0), 7.89(2 \mathrm{H}, \mathrm{dd}, J=7.8,1.3), 8.07(2 \mathrm{H}, \mathrm{s}), 8.70(2 \mathrm{H}, \mathrm{dd}, J=8.5,1.1), 8.85(2 \mathrm{H}, \mathrm{s})$.

${ }^{13} \mathrm{C}$ NMR $\left(126 \mathrm{MHz}\right.$, tetrachloroethane- $\left.d_{2}\right): 57.47,116.07,121.76,122.56,126.67$ (3C), 127.15, 128.53, 129.28, 129.86, 131.08, $131.82,138.01,138.11,191.01$.

\section{8,17-dihydro-8,17-methanodibenzo[a,n]pentacen-19-one(9b)}<smiles>O=C1c2cc3c(ccc4ccccc43)cc2C2CC1c1cc3ccccc3cc12</smiles>

${ }^{1} \mathrm{H}$ NMR $\left(500 \mathrm{MHz}\right.$, tetrachloroethane- $\left.d_{2}\right): 5.16(1 \mathrm{H}, \mathrm{s}), 5.27(1 \mathrm{H}, \mathrm{s}), 7.62(2 \mathrm{H}$, ddd, $J=8.0,7.0,1.1), 7.69(2 \mathrm{H}, \mathrm{ddd}, J=8.3,7.0,1.4)$, $7.74(2 \mathrm{H}, \mathrm{d}, J=9.0), 7.76(2 \mathrm{H}, \mathrm{d}, J=9.0), 7.89(2 \mathrm{H}, \mathrm{dd}, J=7.9,1.4), 8.05(2 \mathrm{H}, \mathrm{s}), 8.71(2 \mathrm{H}, \mathrm{d}, J=8.2), 8.87(2 \mathrm{H}, \mathrm{s})$.

${ }^{13} \mathrm{C}$ NMR $\left(126 \mathrm{MHz}\right.$, tetrachloroethane- $\left.d_{2}\right): 57.05,57.90,116.09,121.75,122.56,126.67$ (3C), 127.15, 128.54, 129.30, 129.88, 131.07, 131.82, 137.92, 138.21, 191.00 .

(1S)-13,13-dimethoxy-2,3-dimethylene-1,2,3,4,5,12-hexahydro-1,4-methanotetracene (10)<smiles>C=C1C(=C)C2C(=C)CC1C1=C2Cc2cc3ccccc3cc2C1</smiles>

${ }^{1} \mathrm{H}$ NMR $\left(300 \mathrm{MHz}, \mathrm{CD}_{2} \mathrm{Cl} 2\right): 3.21(3 \mathrm{H}, \mathrm{s}), 3.22(3 \mathrm{H}, \mathrm{s}), 3.39(2 \mathrm{H}, \mathrm{s}), 3.52-3.64(2 \mathrm{H}, \mathrm{m}), 3.67-3.79(2 \mathrm{H}, \mathrm{m}), 4.98(2 \mathrm{H}, \mathrm{s}), 5.19(2 \mathrm{H}, \mathrm{s})$, 7.36-7.41 (2H, m), $7.65(2 \mathrm{H}, \mathrm{s}), 7.71-7.77(2 \mathrm{H}, \mathrm{m})$.

${ }^{13} \mathrm{C}$ NMR $(75 \mathrm{MHz}, \mathrm{CDCl} 3): 29.12,50.56,52.10,58.16,101.79,118.25,125.80,127.56,127.78,132.76,133.16,136.24,147.53$.

(8R)-19,19-dimethoxy-8,17-dihydro-8,17-methanobenzo[a]hexacene (11)

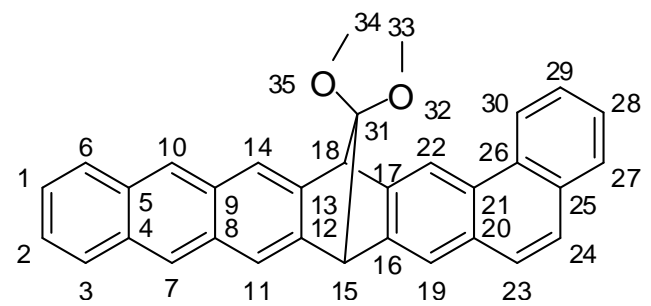

${ }^{1} \mathrm{H}$ NMR $\left(500 \mathrm{MHz}, \mathrm{CD}_{2} \mathrm{Cl}_{2}\right)$ : $3.27(3 \mathrm{H}, \mathrm{s}, H 34), 3.29(3 \mathrm{H}, \mathrm{s}, H 33), 4.82(1 \mathrm{H}, \mathrm{d}, J=1.6, H 15), 4.87(1 \mathrm{H}, \mathrm{d}, J=1.5, H 18), 7.43(2 \mathrm{H}, \mathrm{dd}$, $J=6.6,3.1, H 1, H 2), 7.56(1 \mathrm{H}, \mathrm{ddd}, J=8.0,7.0,1.2, H 28), 7.65(1 \mathrm{H}, \mathrm{ddd}, J=8.4,7.0,1.4, H 29), 7.68-7.72\left(2 \mathrm{H}, \mathrm{ABq}, J_{\mathrm{AB}}=9.2\right.$, 
H23,24), $7.85(1 \mathrm{H}, \mathrm{s}, H 19), 7.86(1 \mathrm{H}, \mathrm{dd}, J=8.7,0.9, H 27), 7.87(1 \mathrm{H}, \mathrm{s}, H 11), 7.89(1 \mathrm{H}, \mathrm{s}, H 14), 7.94-7.97(2 \mathrm{H}, \mathrm{m}, H 3, H 6), 8.29$ $(2 \mathrm{H}, \mathrm{s}, H 7, H 10), 8.67(1 \mathrm{H}, \mathrm{d}, J=8.0, H 30), 8.67(1 \mathrm{H}, \mathrm{s}, H 22)$.

${ }^{13} \mathrm{C}$ NMR (126 MHz, $\mathrm{CD}_{2} \mathrm{Cl}_{2}$ ): 50.94 (C34), 51.13 (C33), 54.71 (C15), 55.15 (C18), 115.91 (C22), 119.99 (C11), 120.01 (C14), 121.56 (C19), 122.49 (C30), 124.73 (C31), 125.04 (C1,C2), 125.73 (C7,C10), 126.08 (C28), 126.28 (C29), 126.30 (C24), 126.83 (C23), 127.81 (C3,C6), 128.40 (C27), 128.84 (C21), 130.25 (C26), 130.80 (C20), 131.01 (C12,C13), 131.51 (C4,C5), 131.96 (C25), 142.69 (C12), 142.77 (C13), 143.84 (C16), 144.06 (C8).

(8R)-8,17-dihydro-8,17-methanobenzo[a]hexacen-19-one (12)<smiles>O=C1c2cc3cc4ccccc4cc3cc2C2CC1c1cc3ccccc3cc12</smiles>

${ }^{1} \mathrm{H}$ NMR $\left(500 \mathrm{MHz}\right.$, tetrachloroethane- $\left.d_{2}\right): 5.08(1 \mathrm{H}, \mathrm{s}), 5.14(1 \mathrm{H}, \mathrm{s}), 7.48(2 \mathrm{H}, \mathrm{dd}, J=6.7,3.2), 7.62(1 \mathrm{H}, \mathrm{ddd}, J=7.9,6.7,0.9), 7.69$ $(1 \mathrm{H}, \mathrm{ddd}, J=8.2,6.9,1.0), 7.74(1 \mathrm{H}, \mathrm{d}, J=9.3), 7.77(1 \mathrm{H}, \mathrm{d}, J=9.3), 7.89(1 \mathrm{H}, \mathrm{d}, J=7.8), 8.00(2 \mathrm{H}, \mathrm{dd}, J=6.6,3.3), 8.04(1 \mathrm{H}, \mathrm{s})$, $8.10(1 \mathrm{H}, \mathrm{s}), 8.12(1 \mathrm{H}, \mathrm{s}), 8.40(2 \mathrm{H}, \mathrm{s}), 8.71(1 \mathrm{H}, \mathrm{d}, J=8.5), 8.85(1 \mathrm{H}, \mathrm{s})$.

${ }^{13} \mathrm{C}$ NMR $\left(126 \mathrm{MHz}\right.$, tetrachloroethane- $\left.d_{2}\right): 56.86,57.29,116.03,120.54,120.55,121.71,122.56,125.49(2 \mathrm{C}), 126.21(2 \mathrm{C}), 126.66$, 126.70 (2C), 127.18, 127.91 (2C), 128.55 (2C), 129.40, 129.86, 130.74 (2C), 131.16, 131.49 (2C), 131.81, 136.40, 136.49, 137.79, 137.97, $193.08(\mathrm{C}=\mathrm{O})$. 

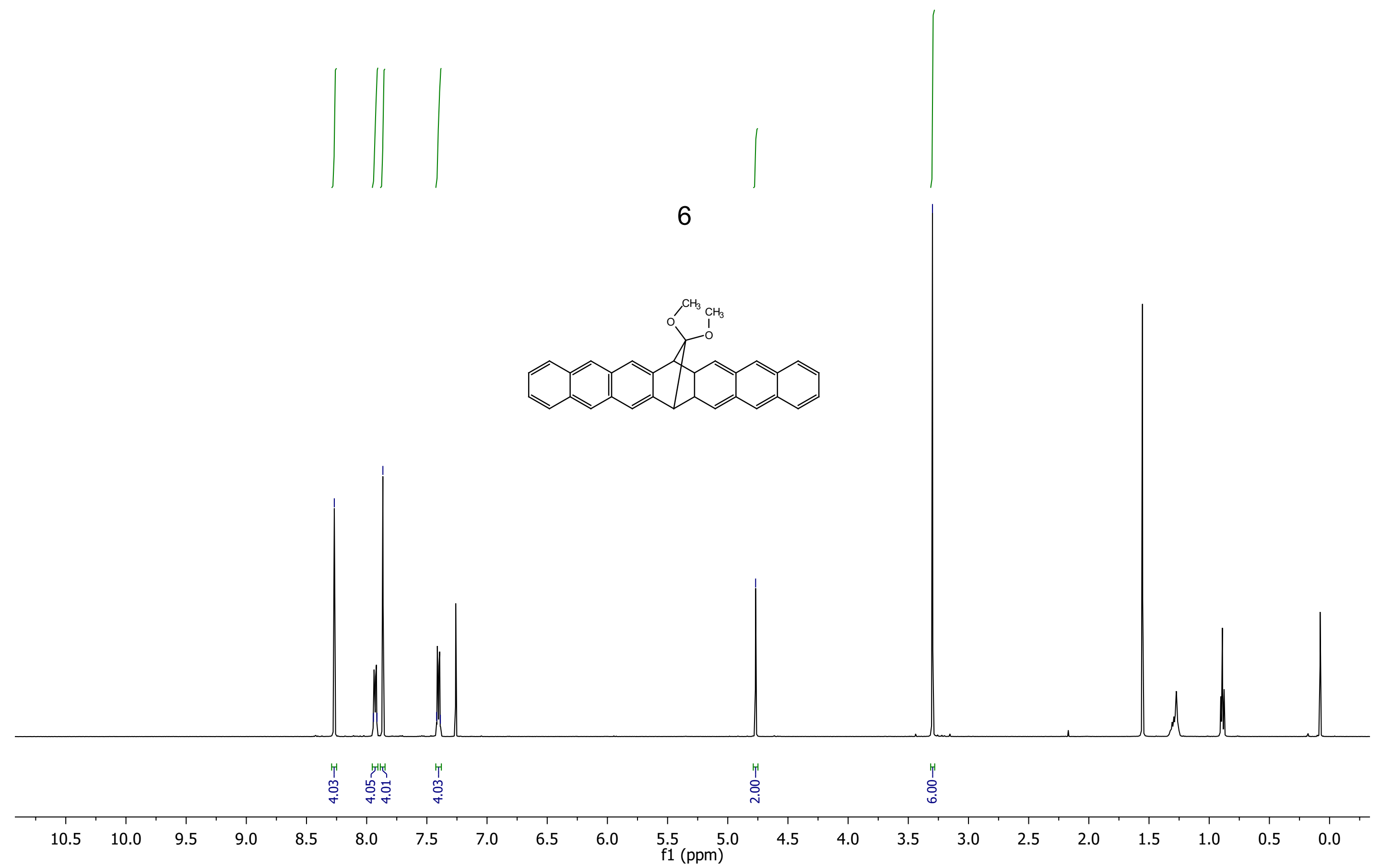
AJ154_500MHz.58.fid

AJ154 cdcl3 13C $\{1 \mathrm{H}\}$

爫

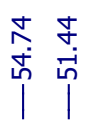

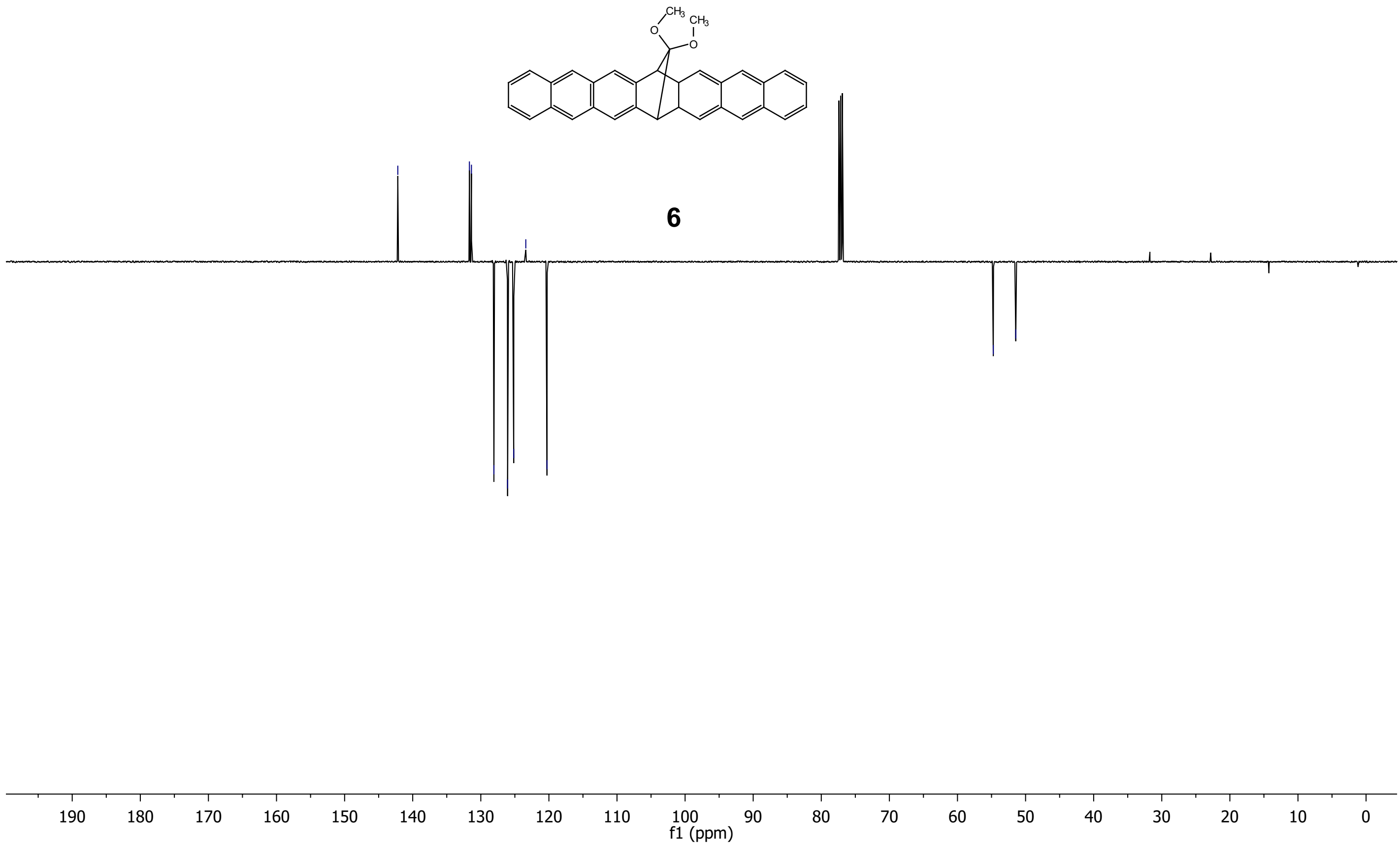



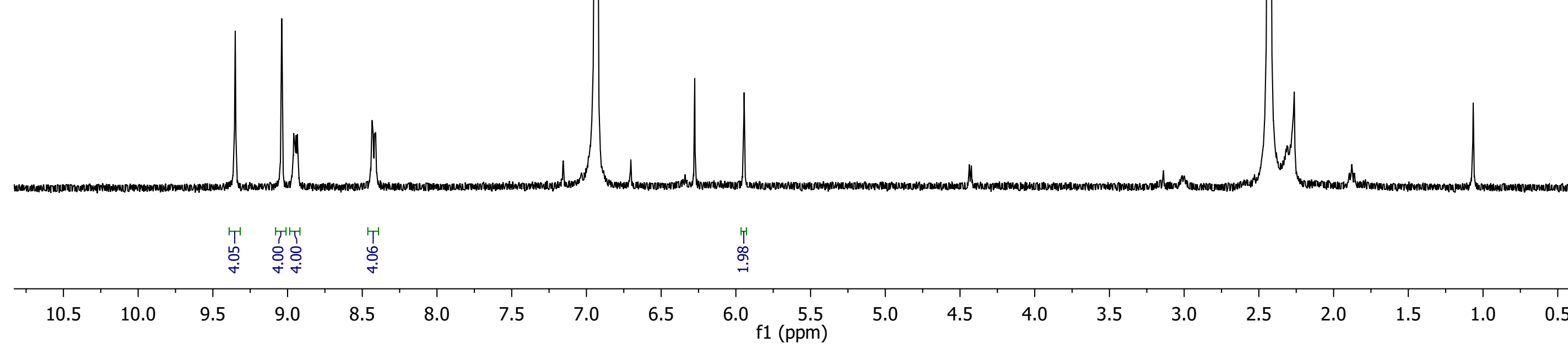


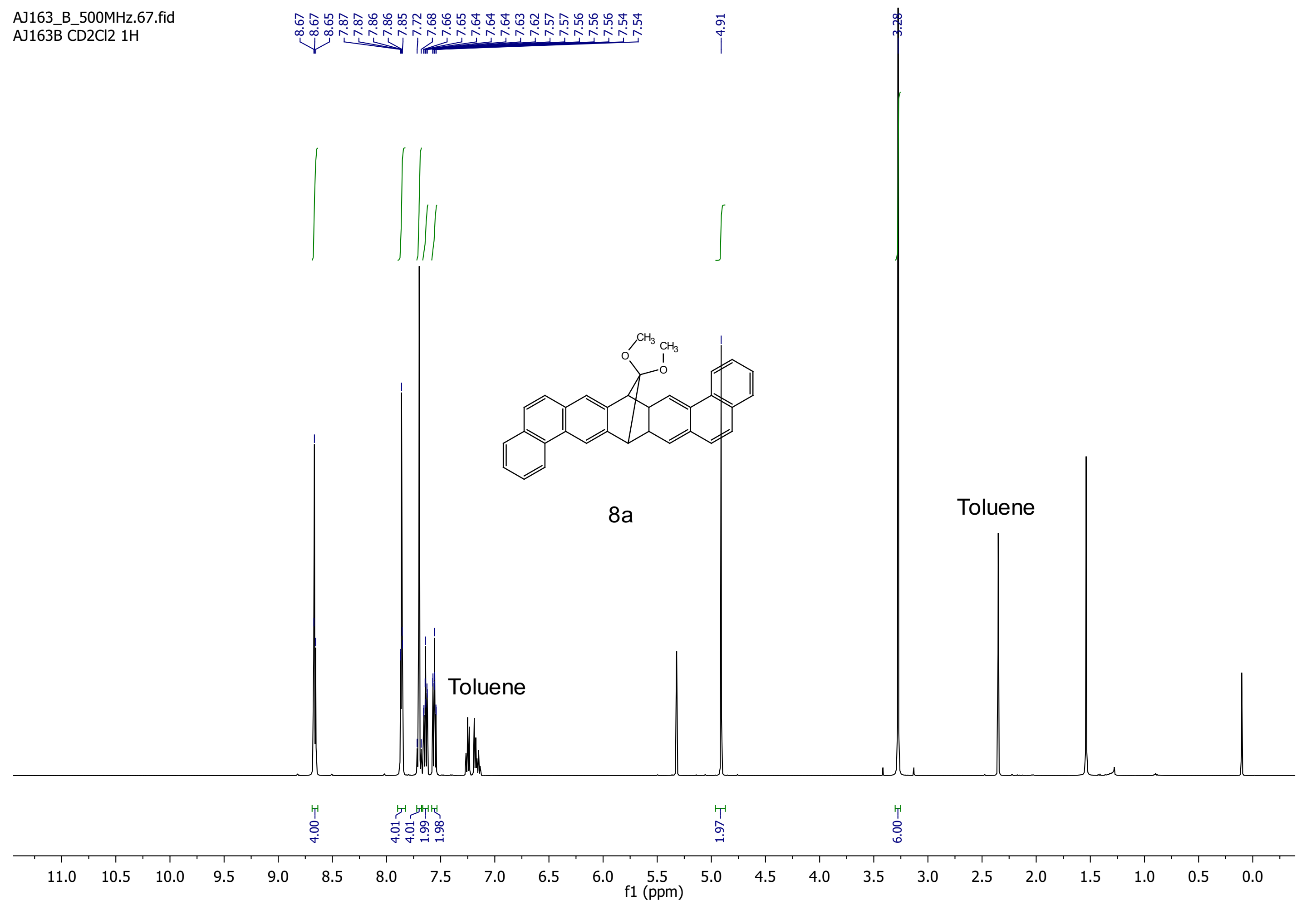




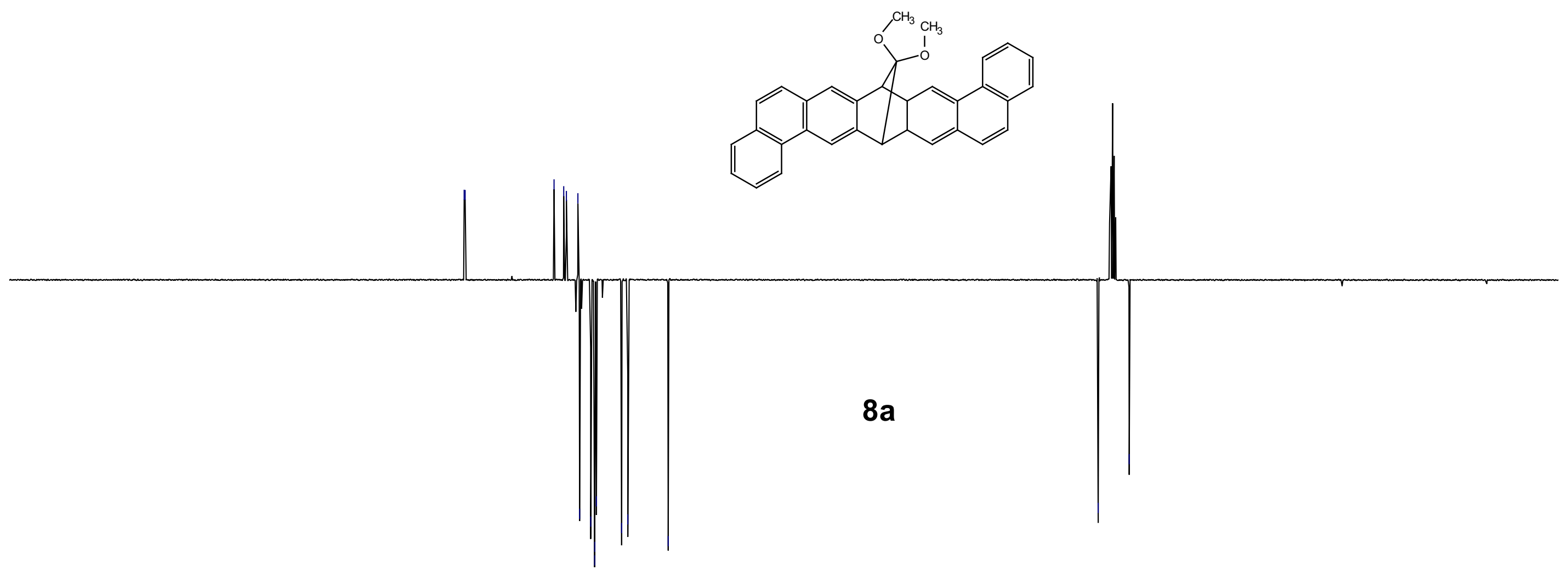

40

$40 \quad 30$



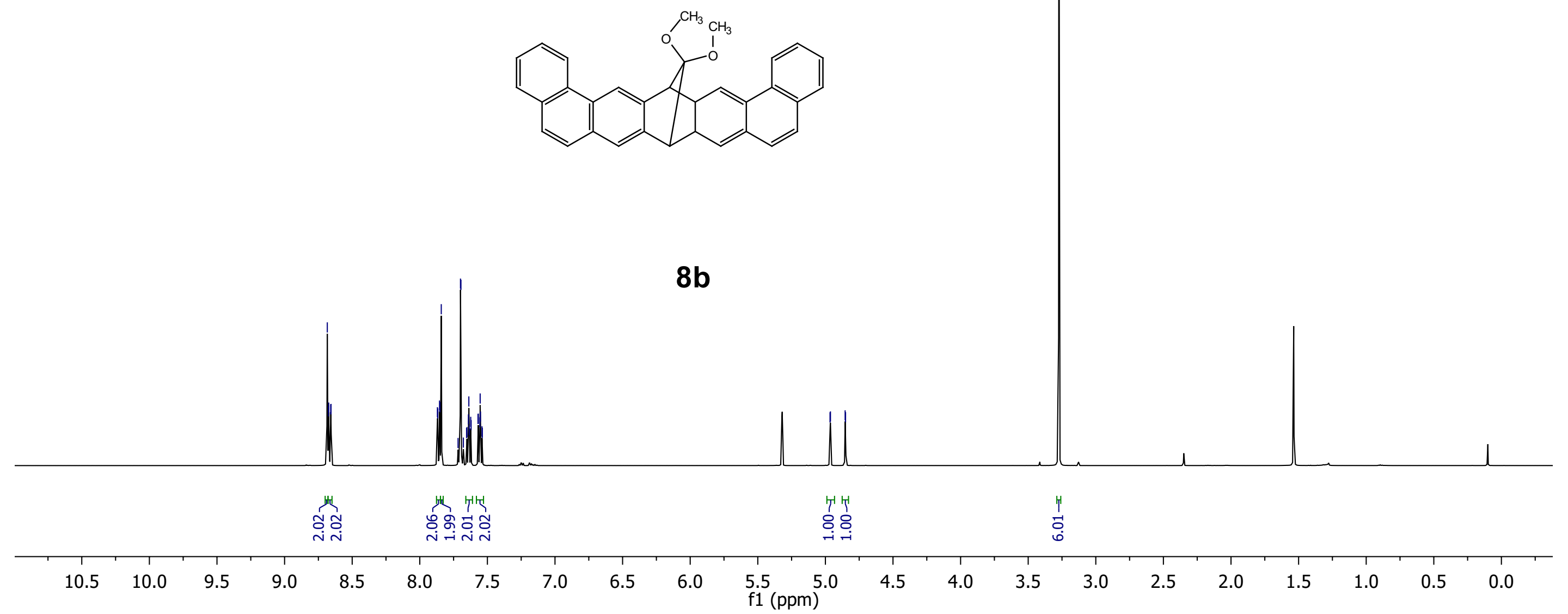

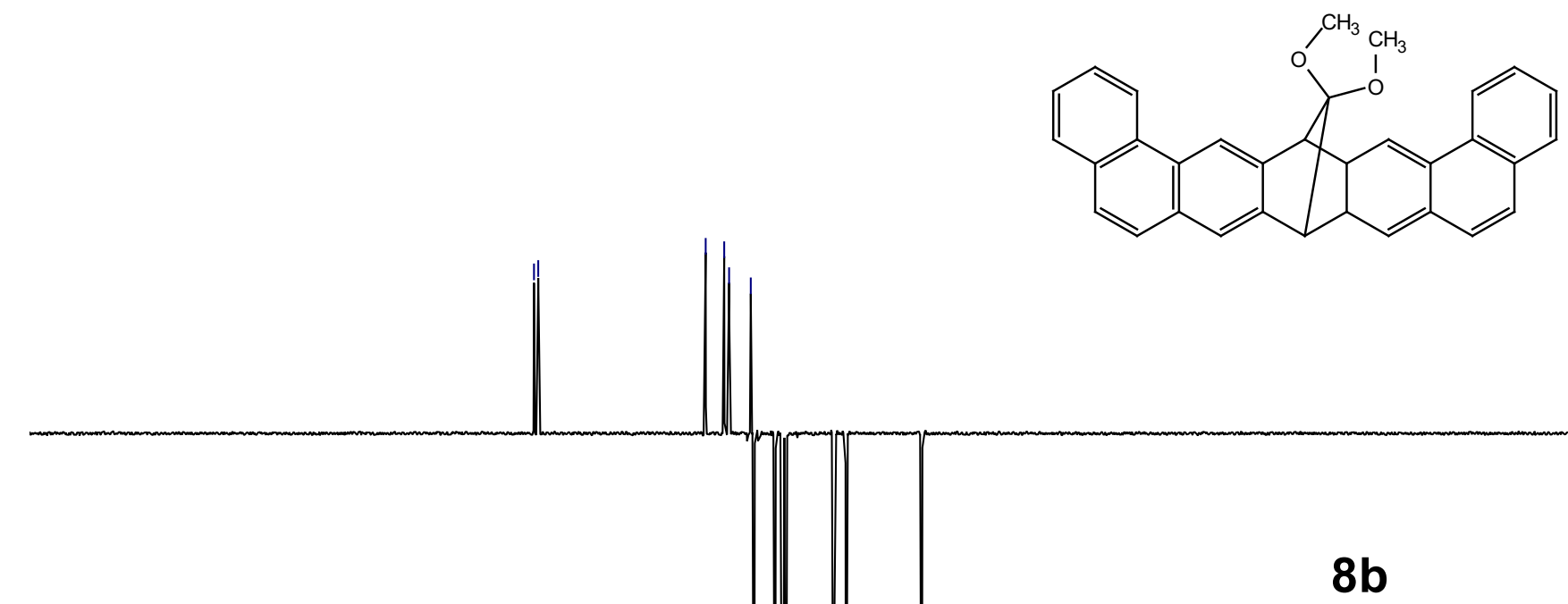


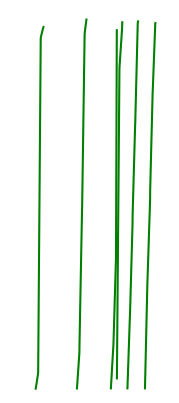

$9 a$

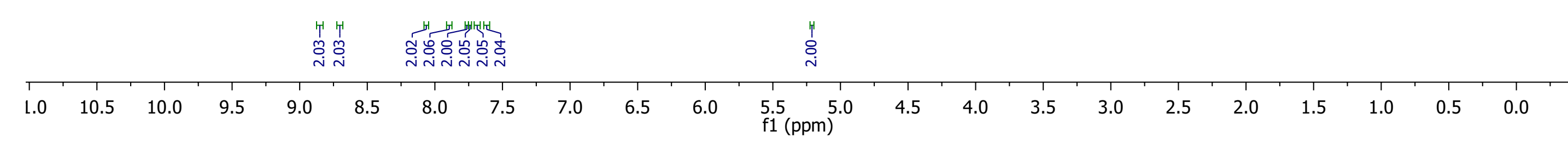




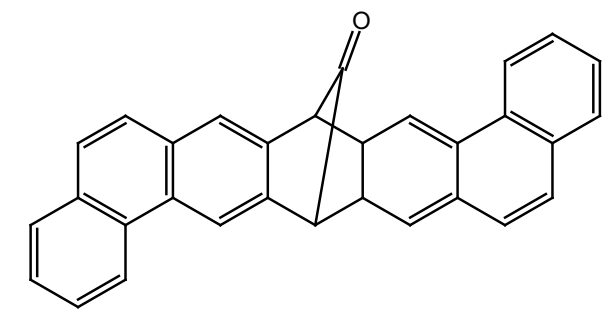

$9 a$

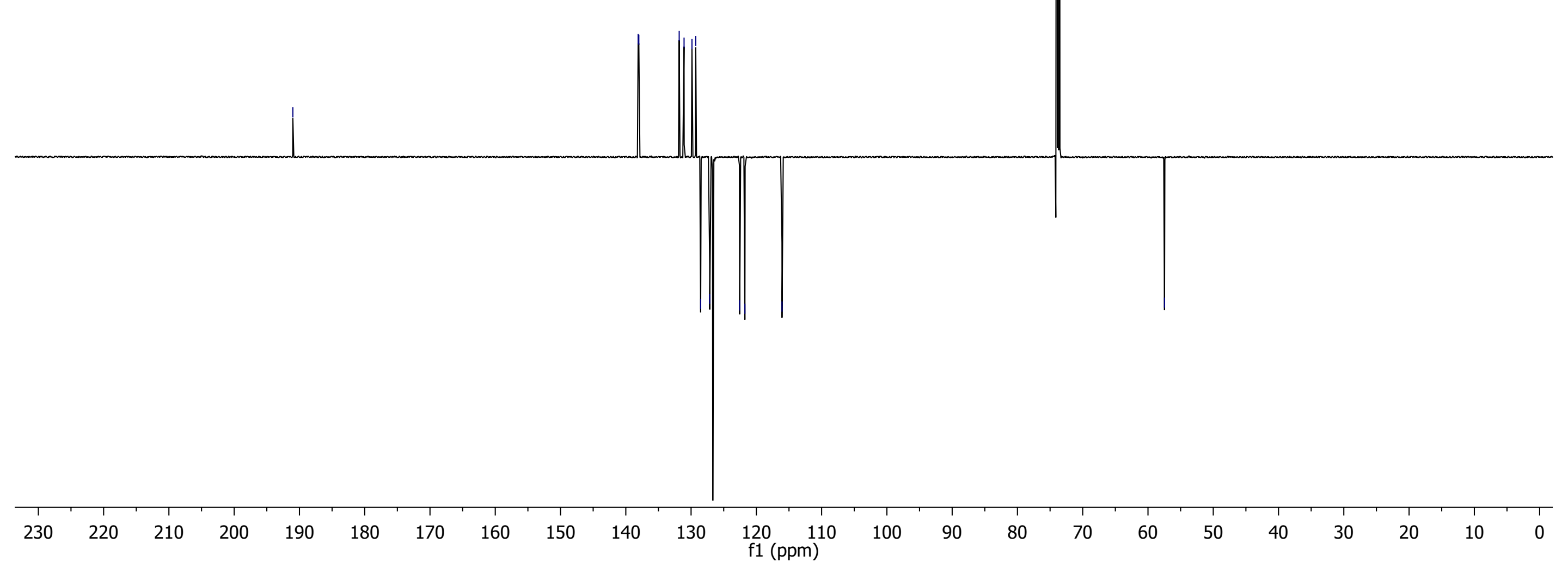




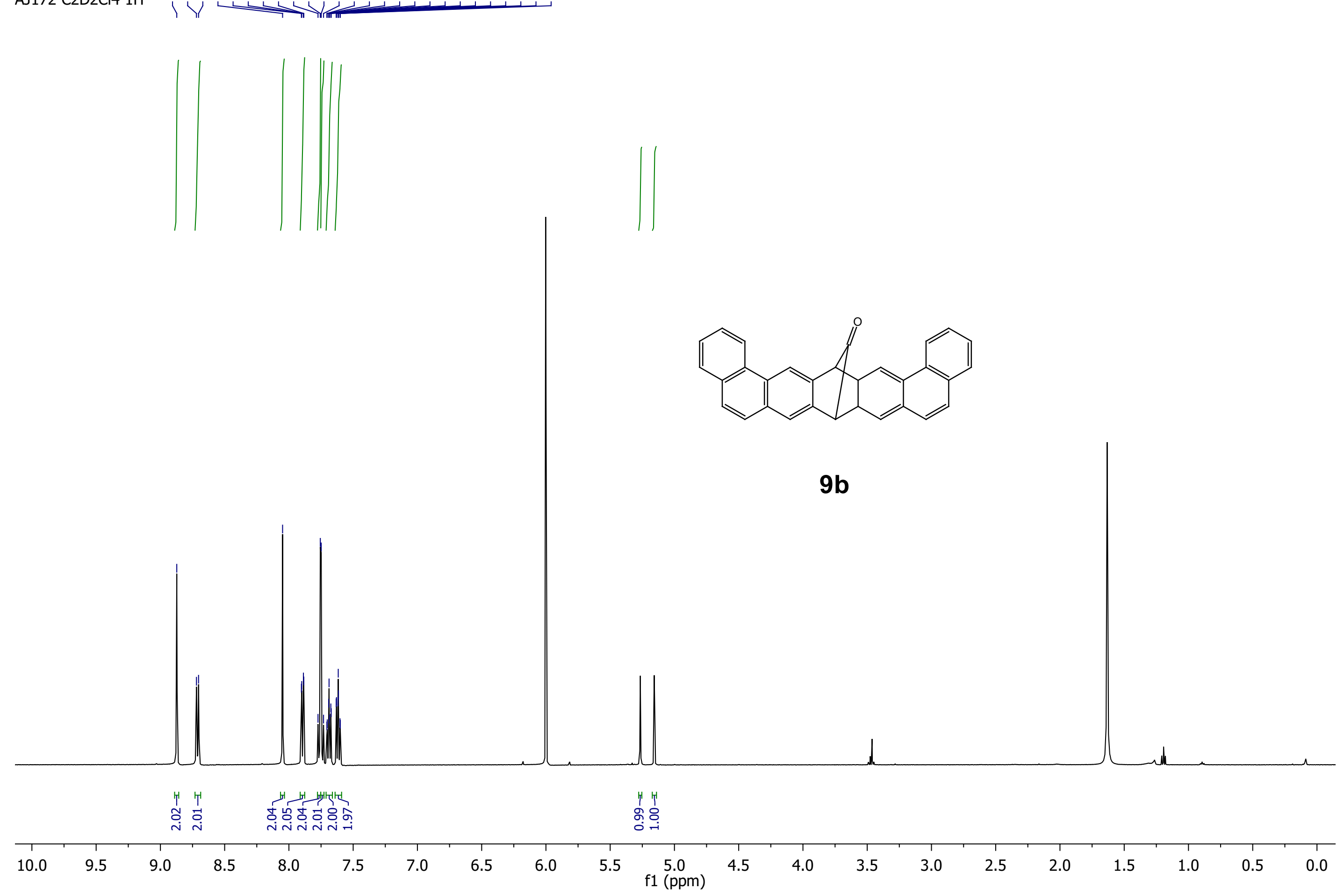




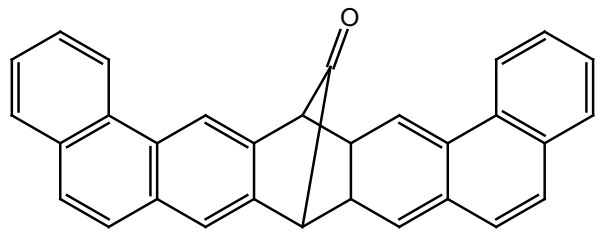

$9 b$

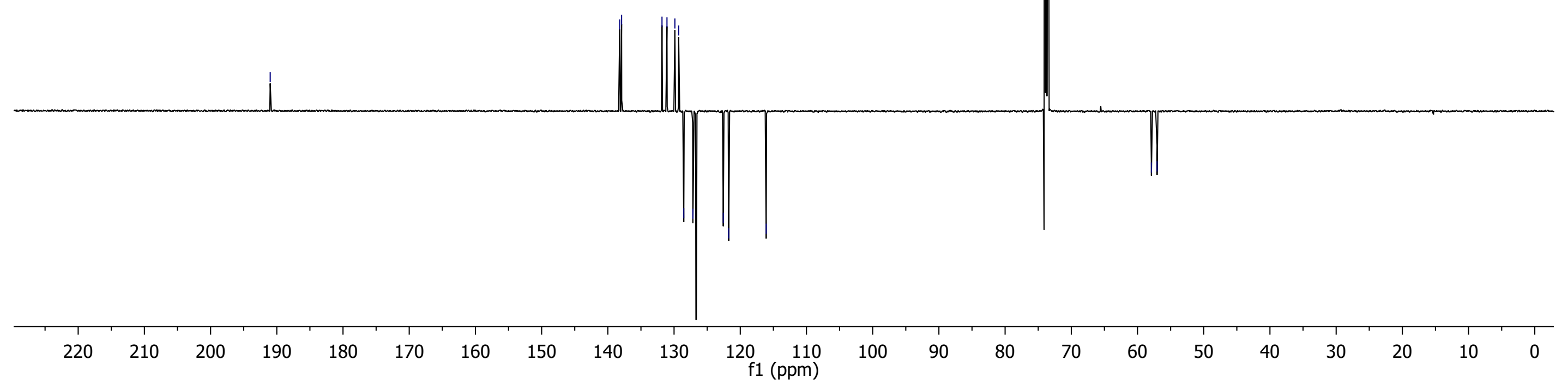



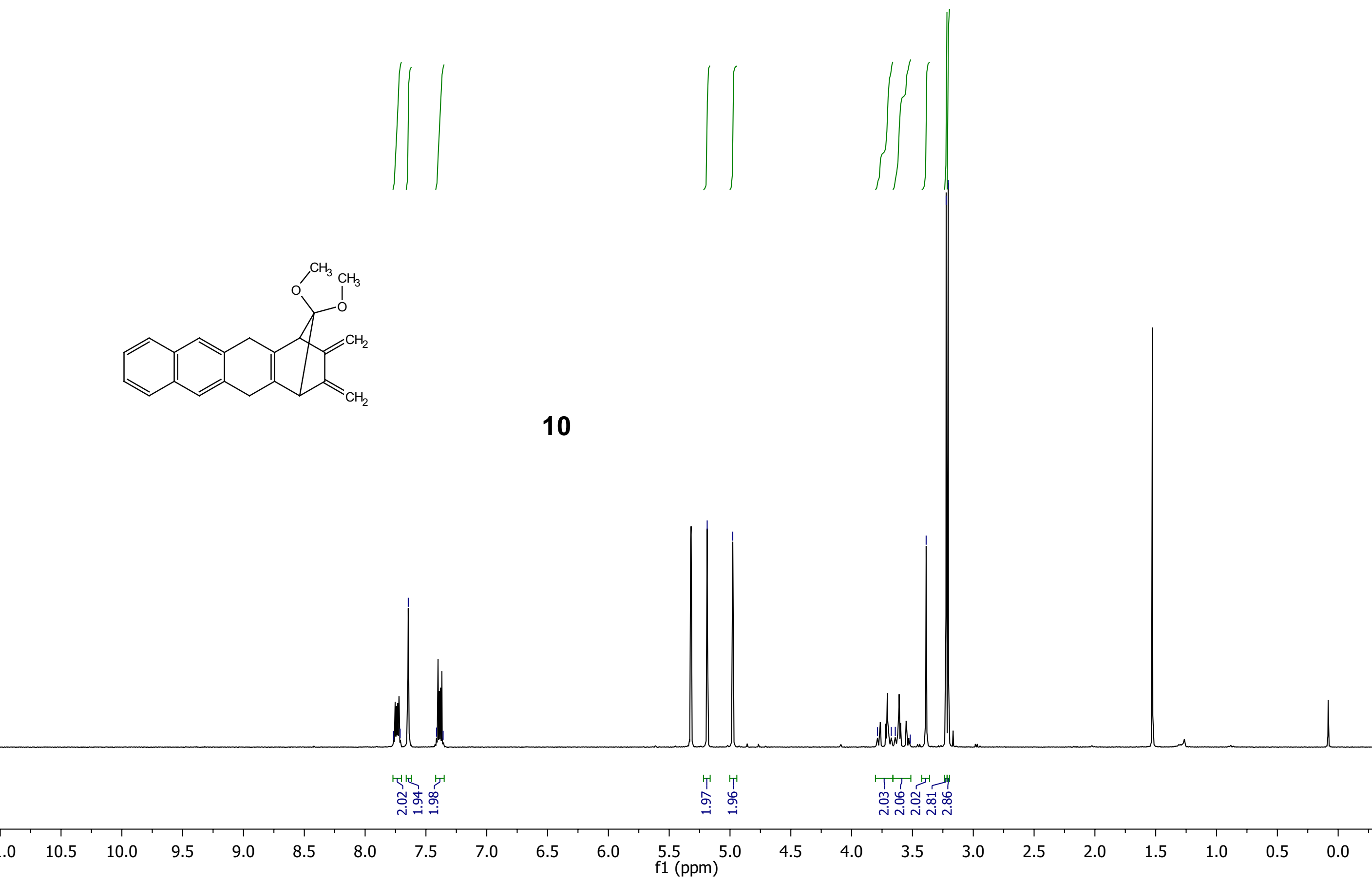


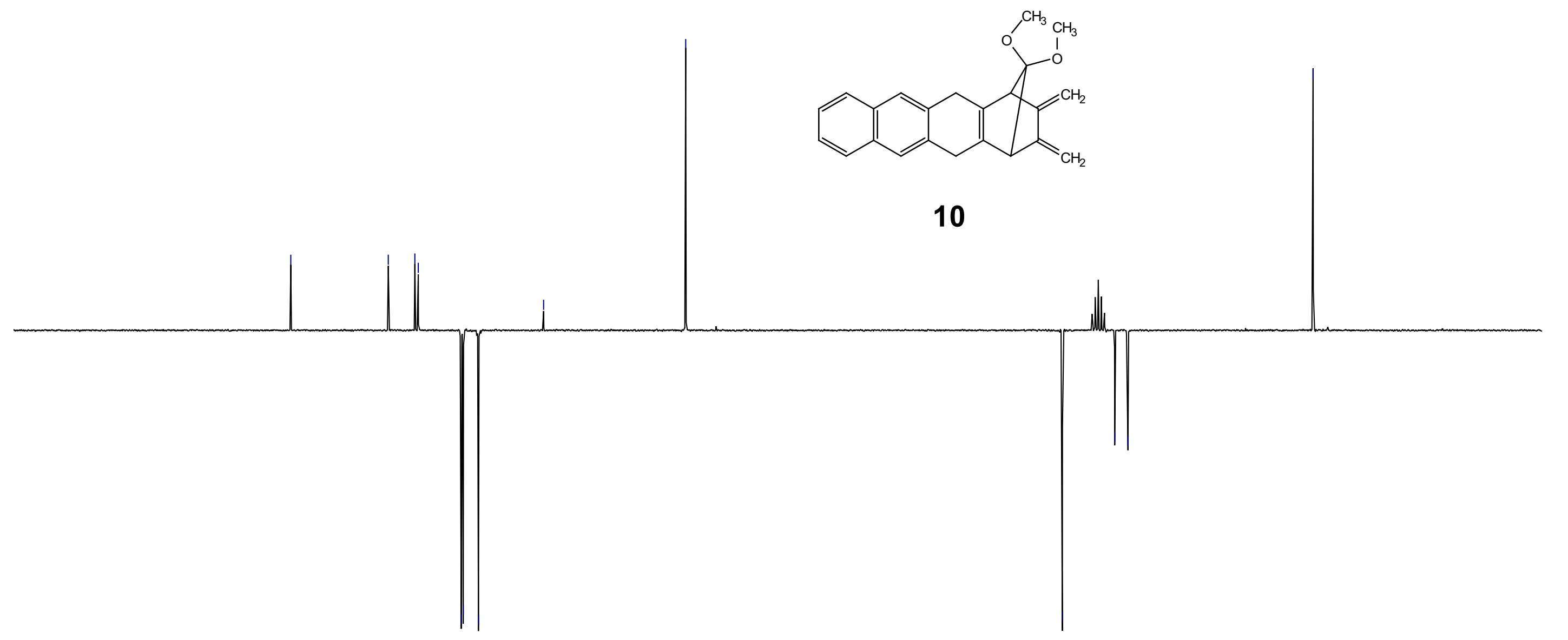

\begin{tabular}{|c|c|c|c|c|c|c|c|c|c|c|c|c|c|c|c|c|}
\hline 170 & 160 & 150 & 140 & 130 & 120 & 110 & 100 & $\begin{array}{c}90 \\
\mathrm{f} 1(\mathrm{ppm})\end{array}$ & 80 & 70 & 60 & 50 & 40 & 30 & 20 & 10 \\
\hline
\end{tabular}



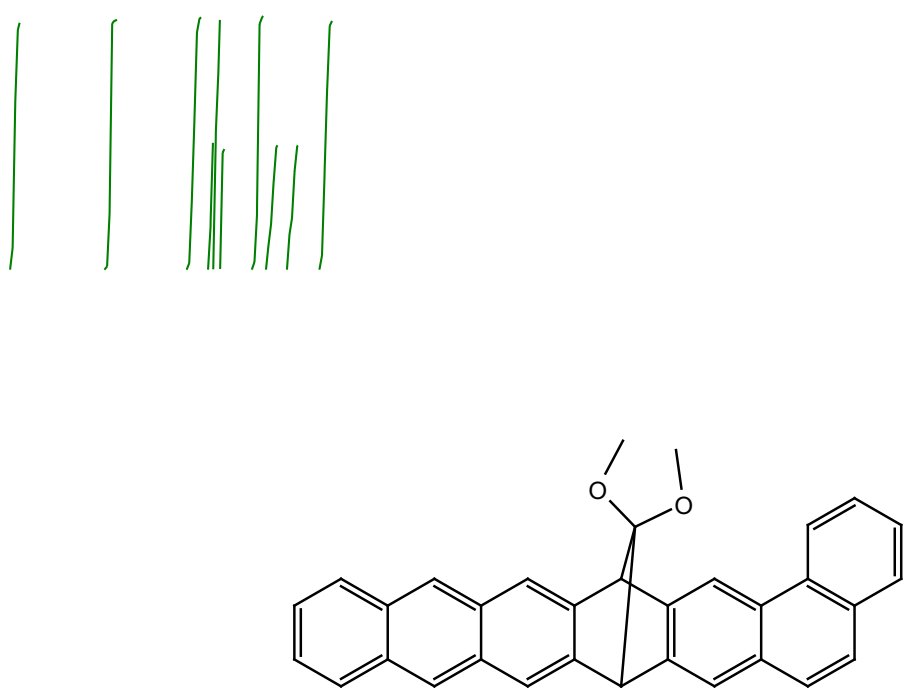

11

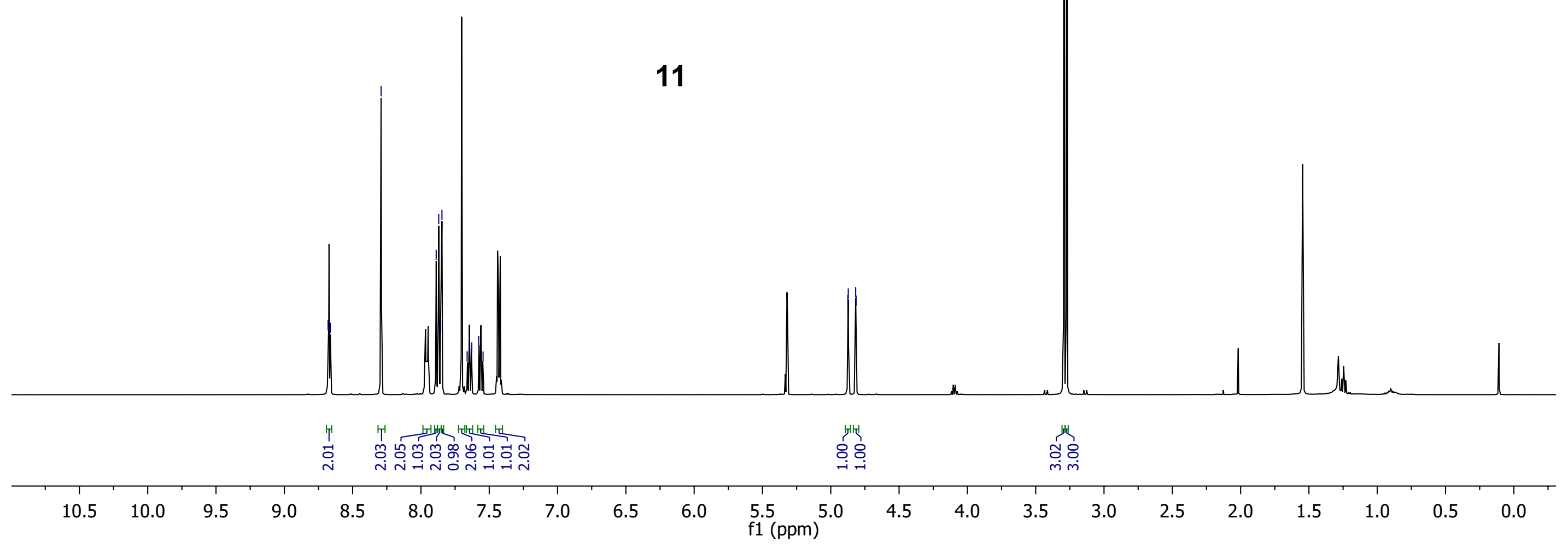



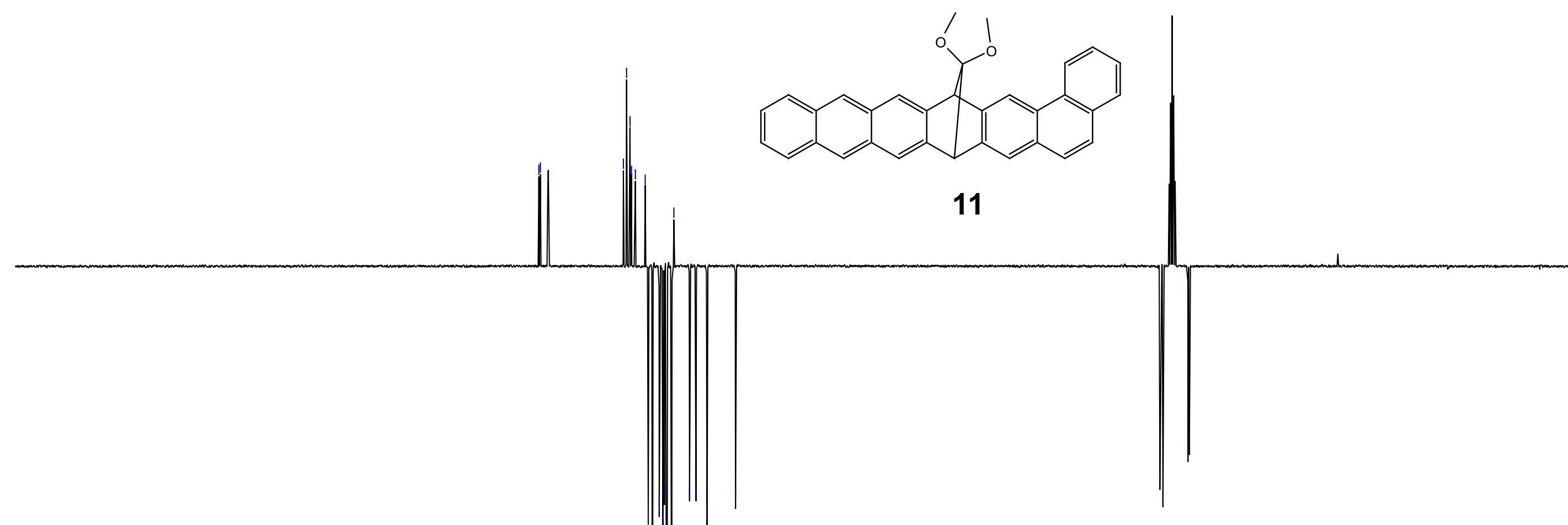

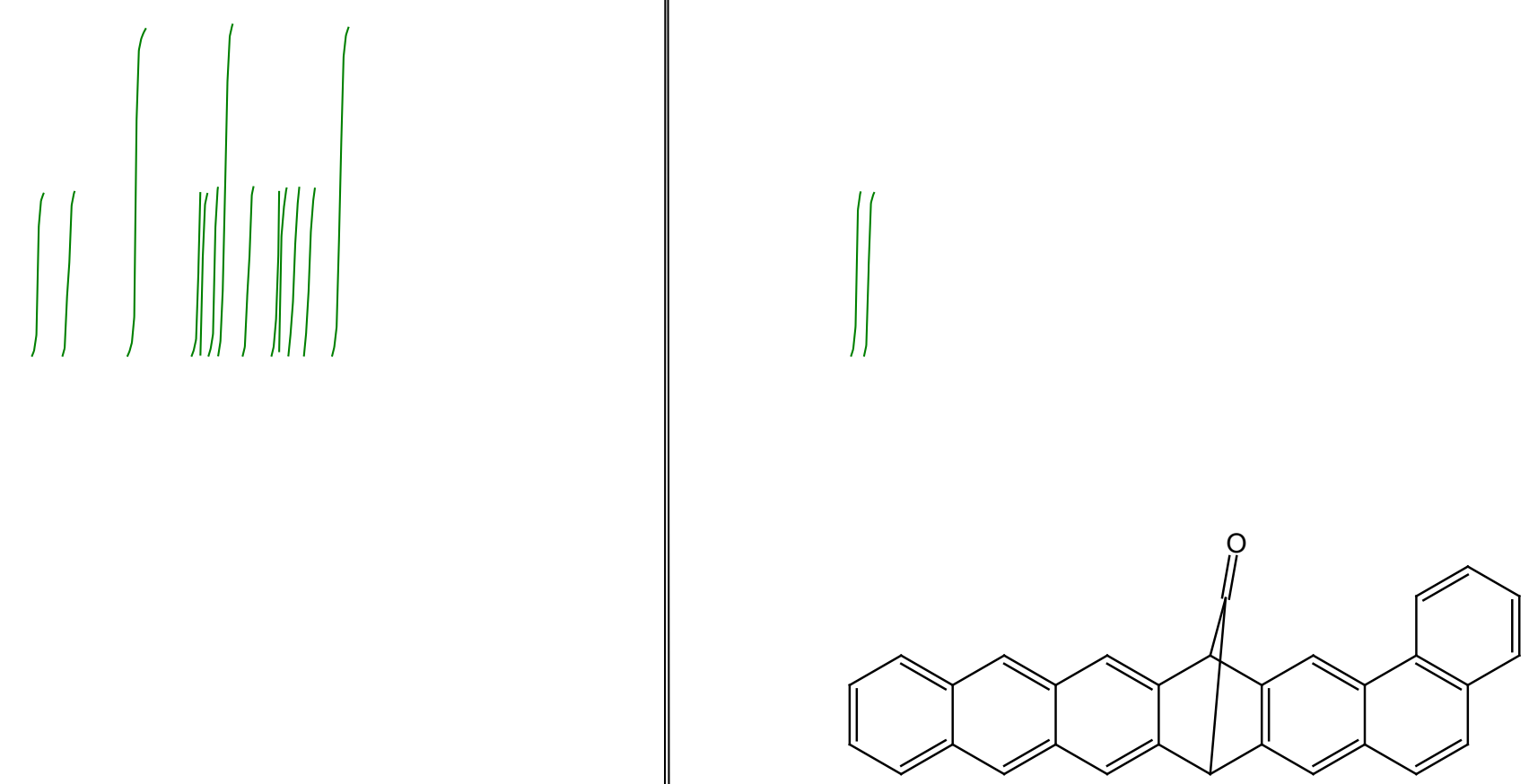

12
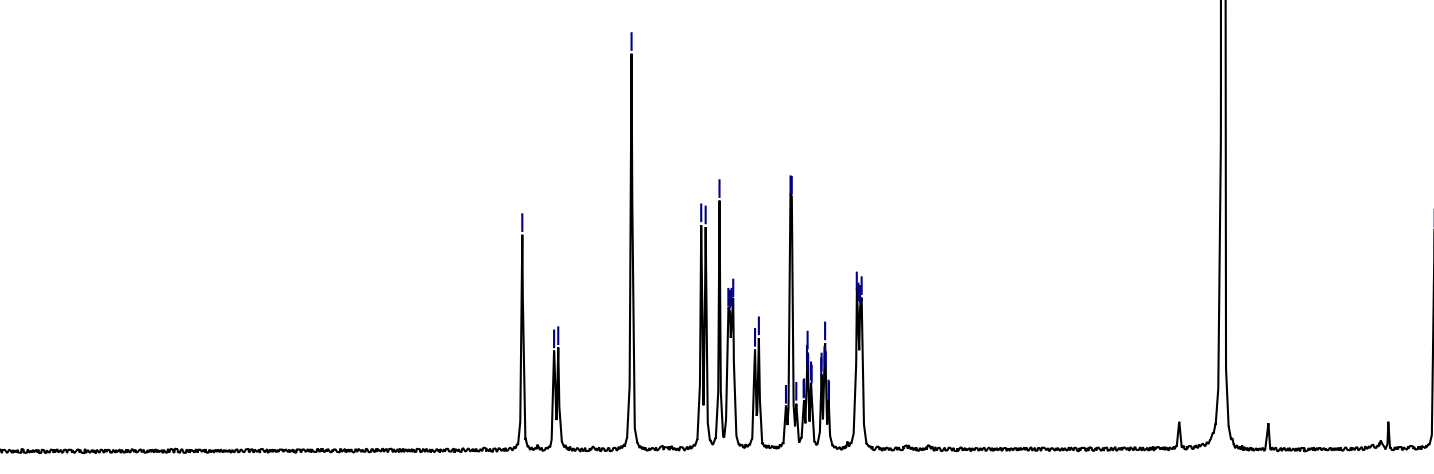

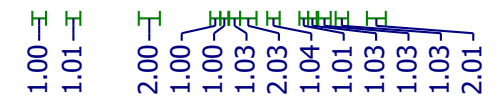

繁 
12
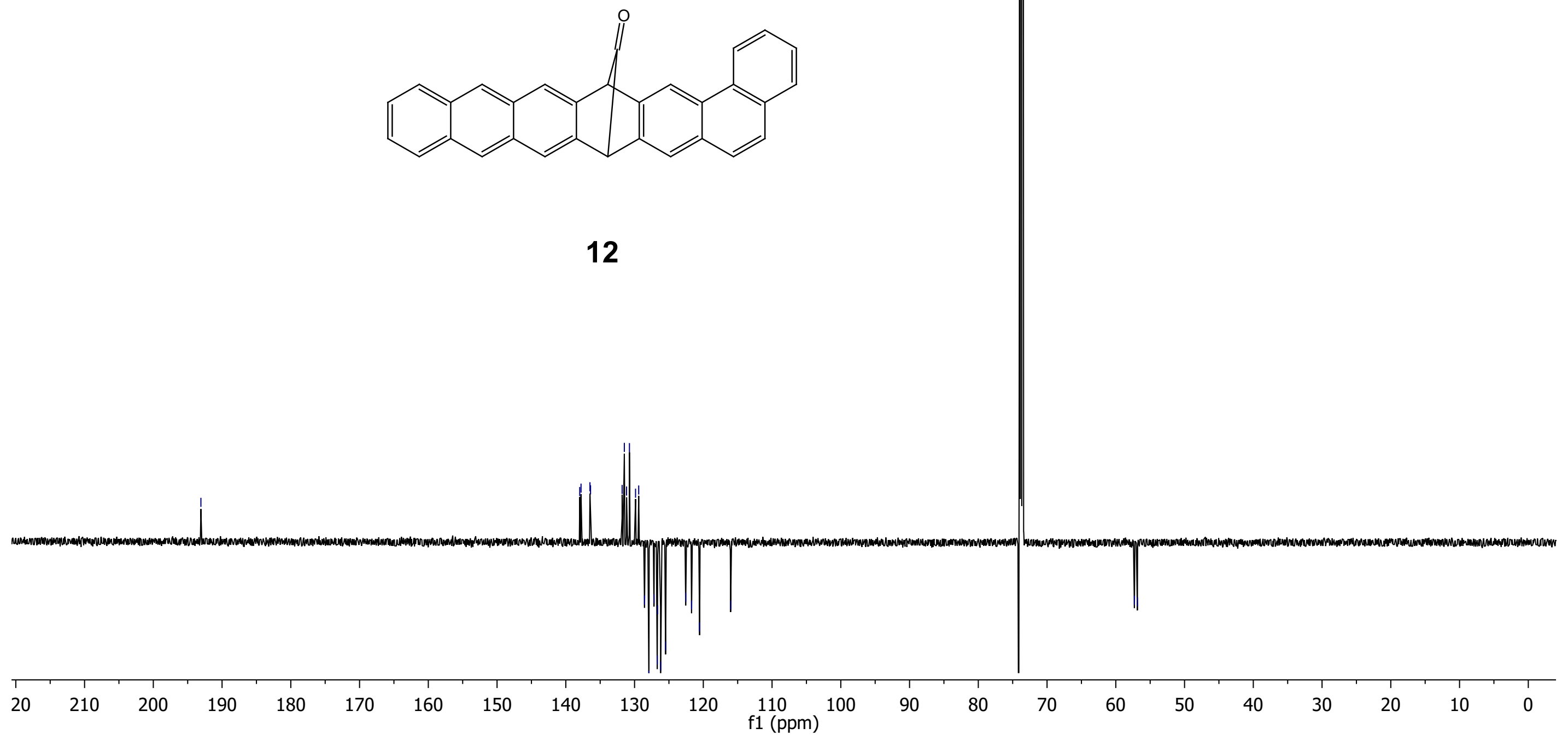


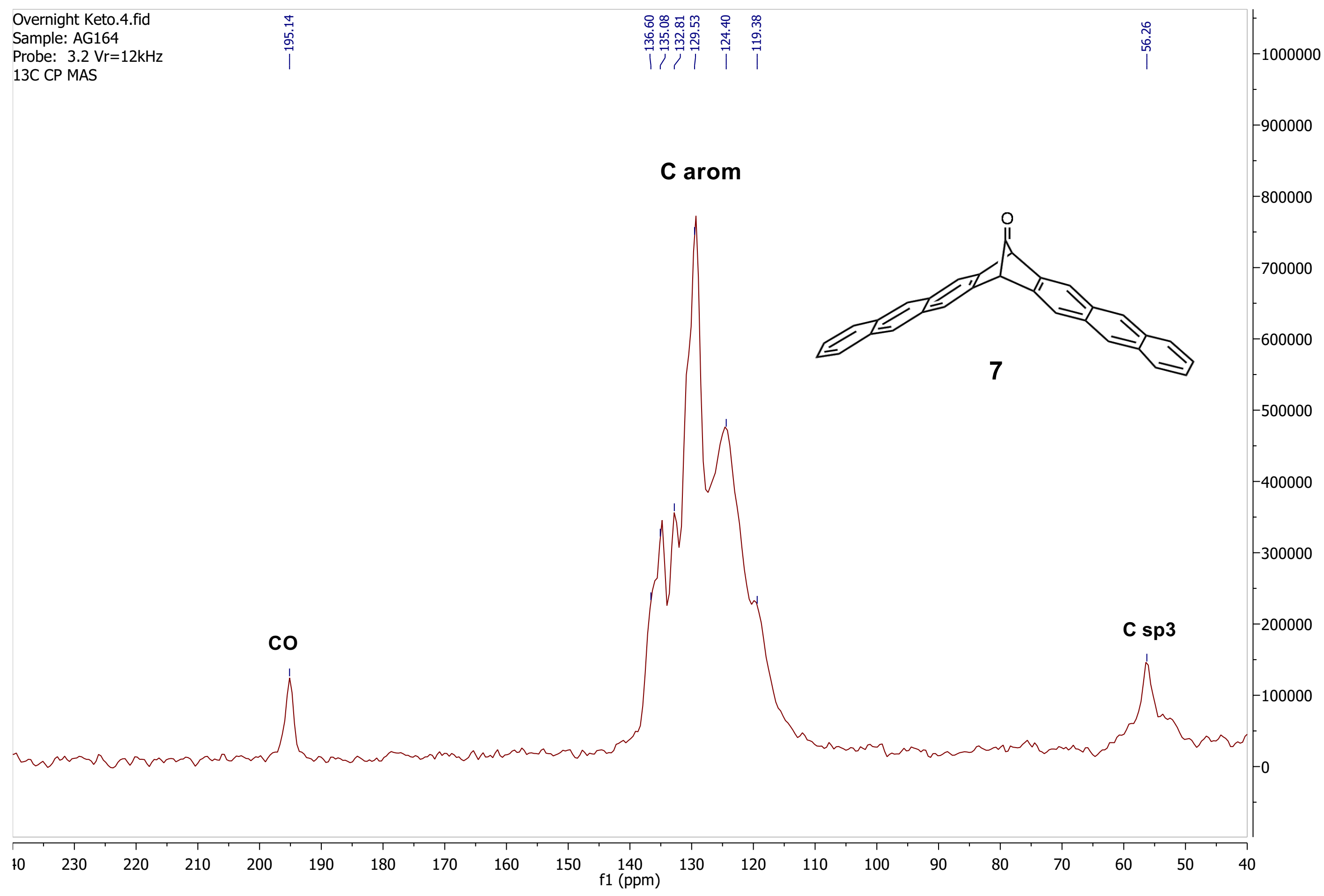




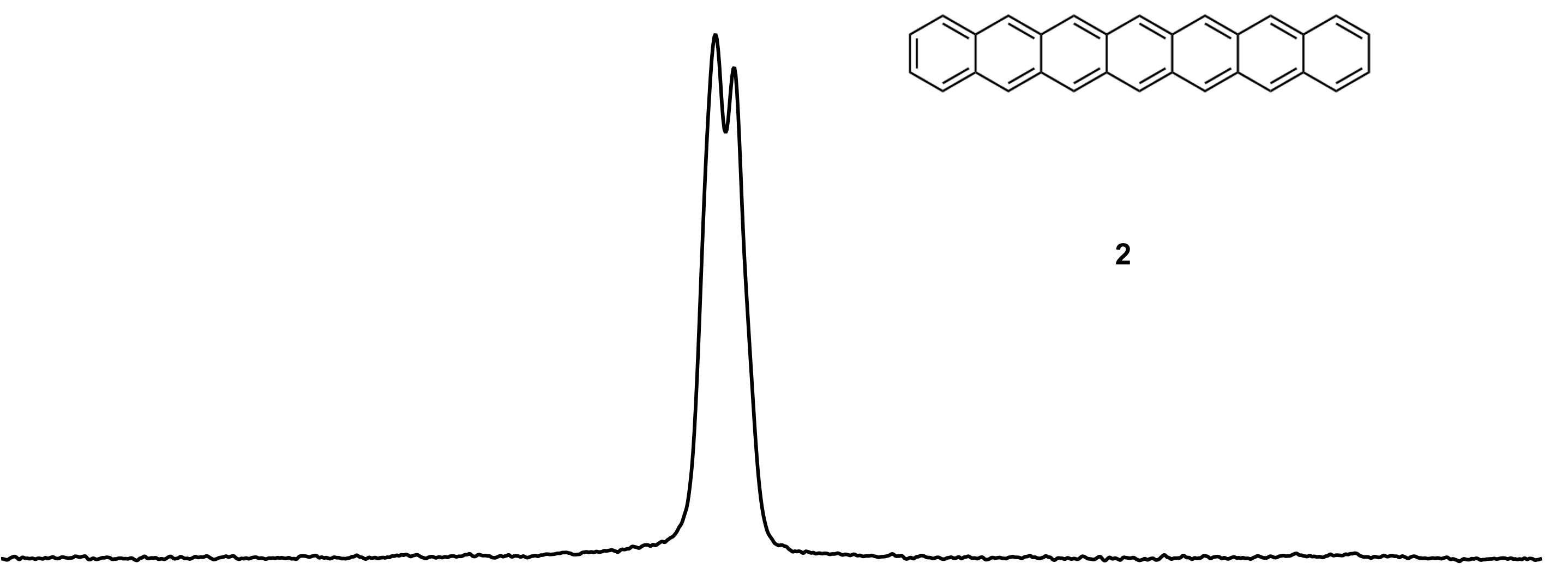




\section{Sample: AJ173}

Probe: $2.5 \mathrm{Vr}=14 \mathrm{kHz}$

13C CP MAS

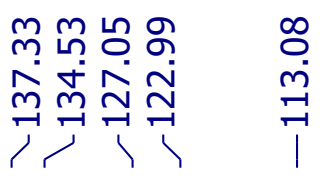

เి

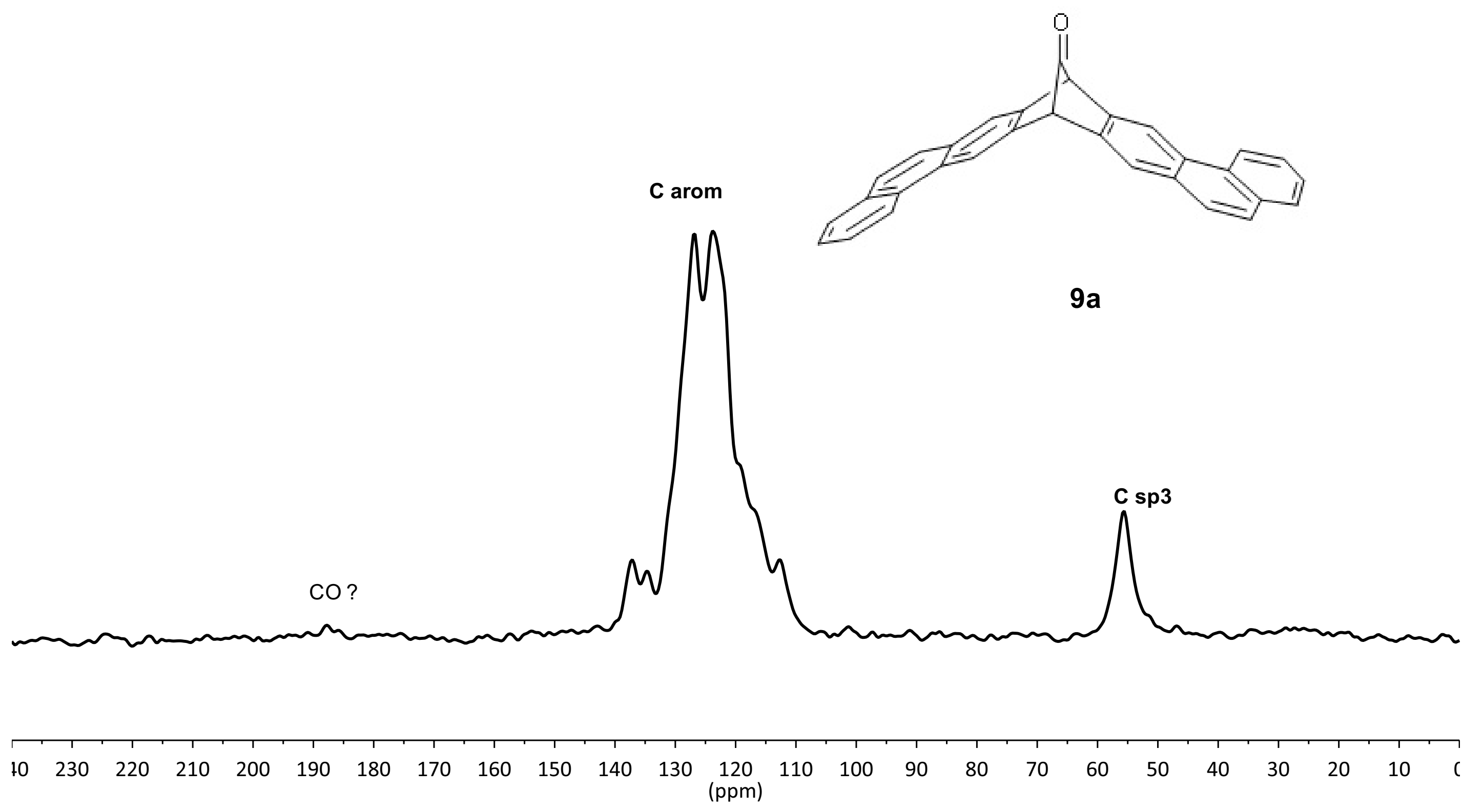




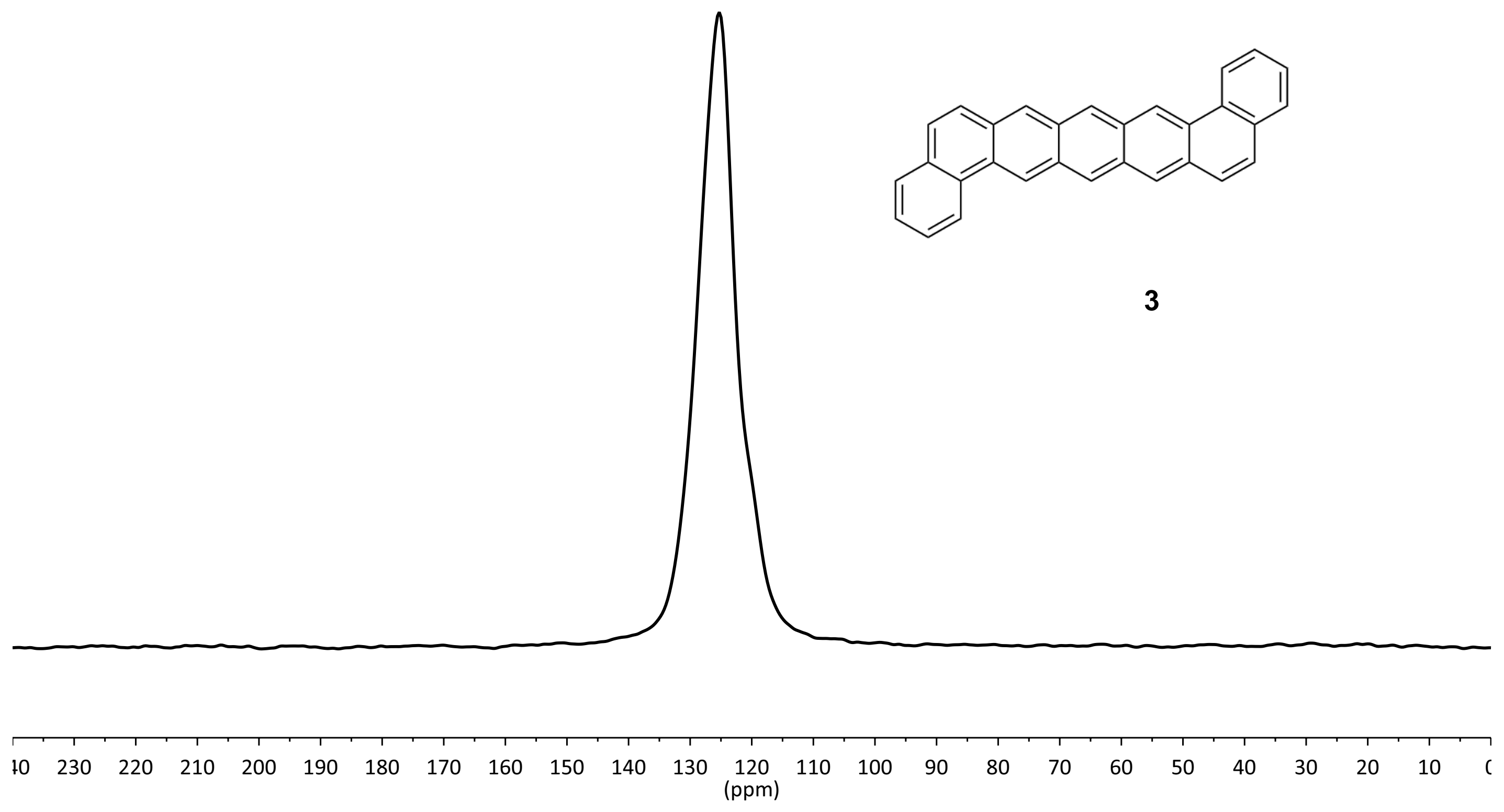




\section{Sample: AJ172}

Probe: $2.5 \mathrm{Vr}=14 \mathrm{kHz}$ 13C CP MAS

\section{C arom}

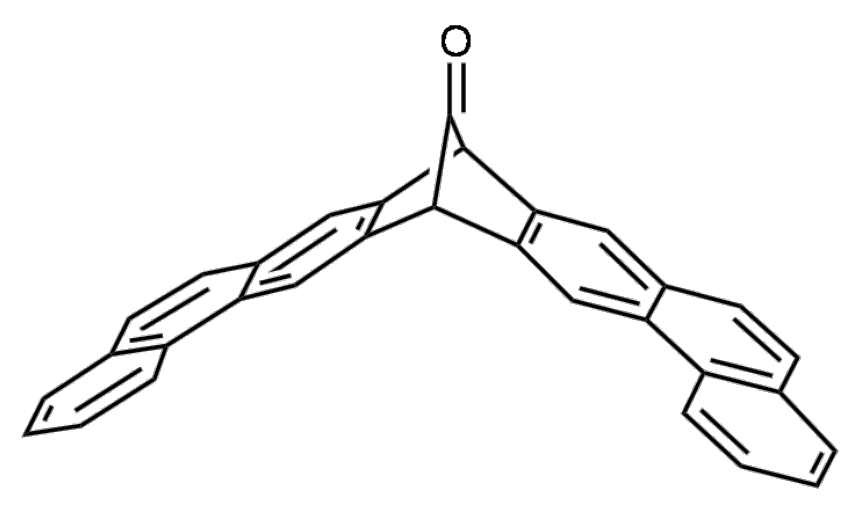

$9 b$

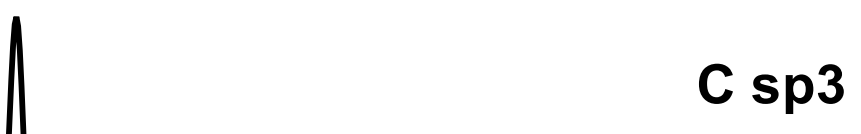

\section{Csp3}

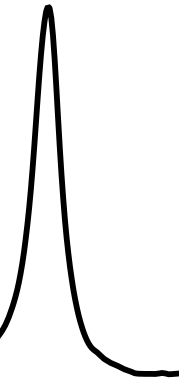




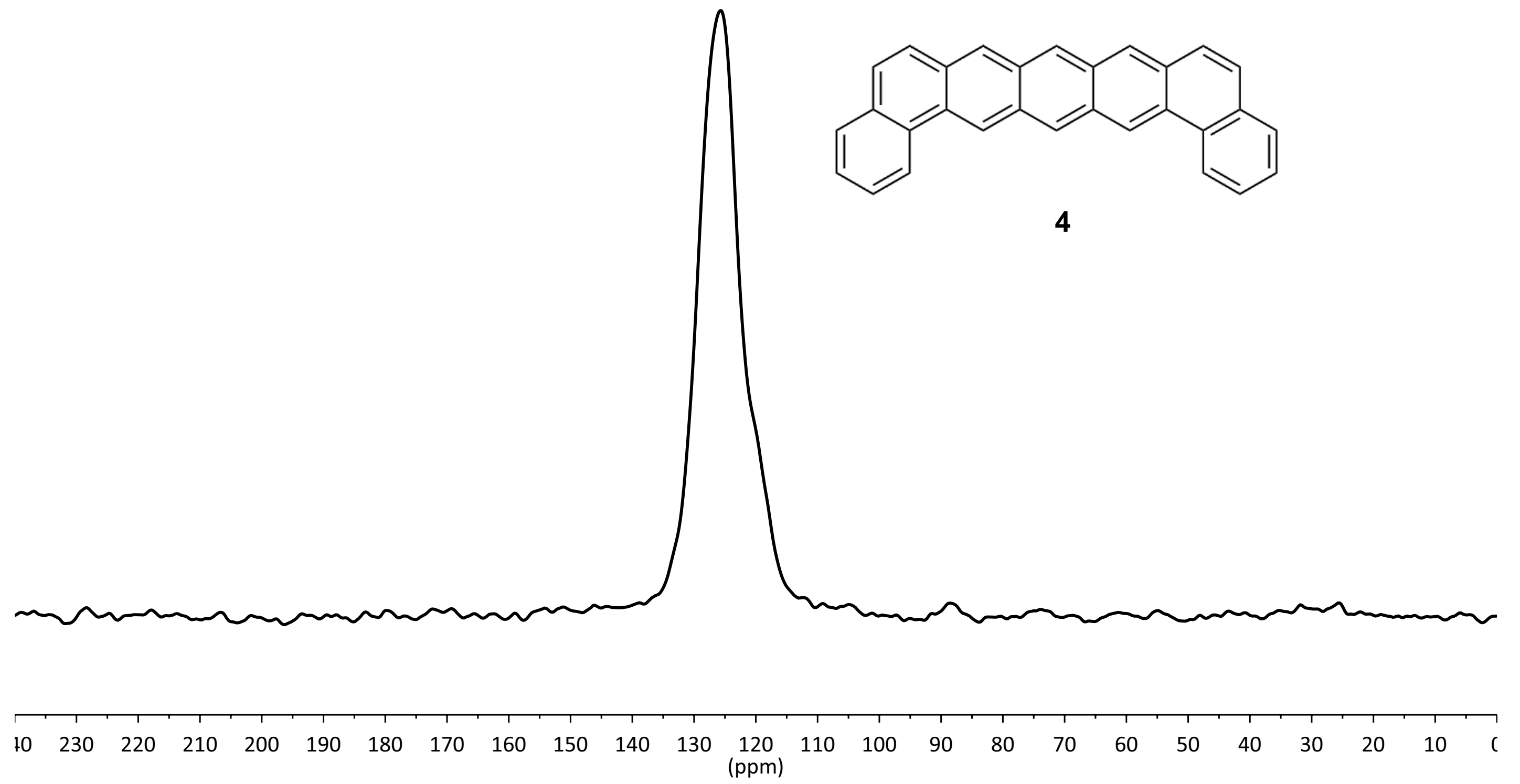


Sample: AJ174 ? Probe: $2.5 \mathrm{Vr}=14 \mathrm{kHz}$ 13C CP MAS

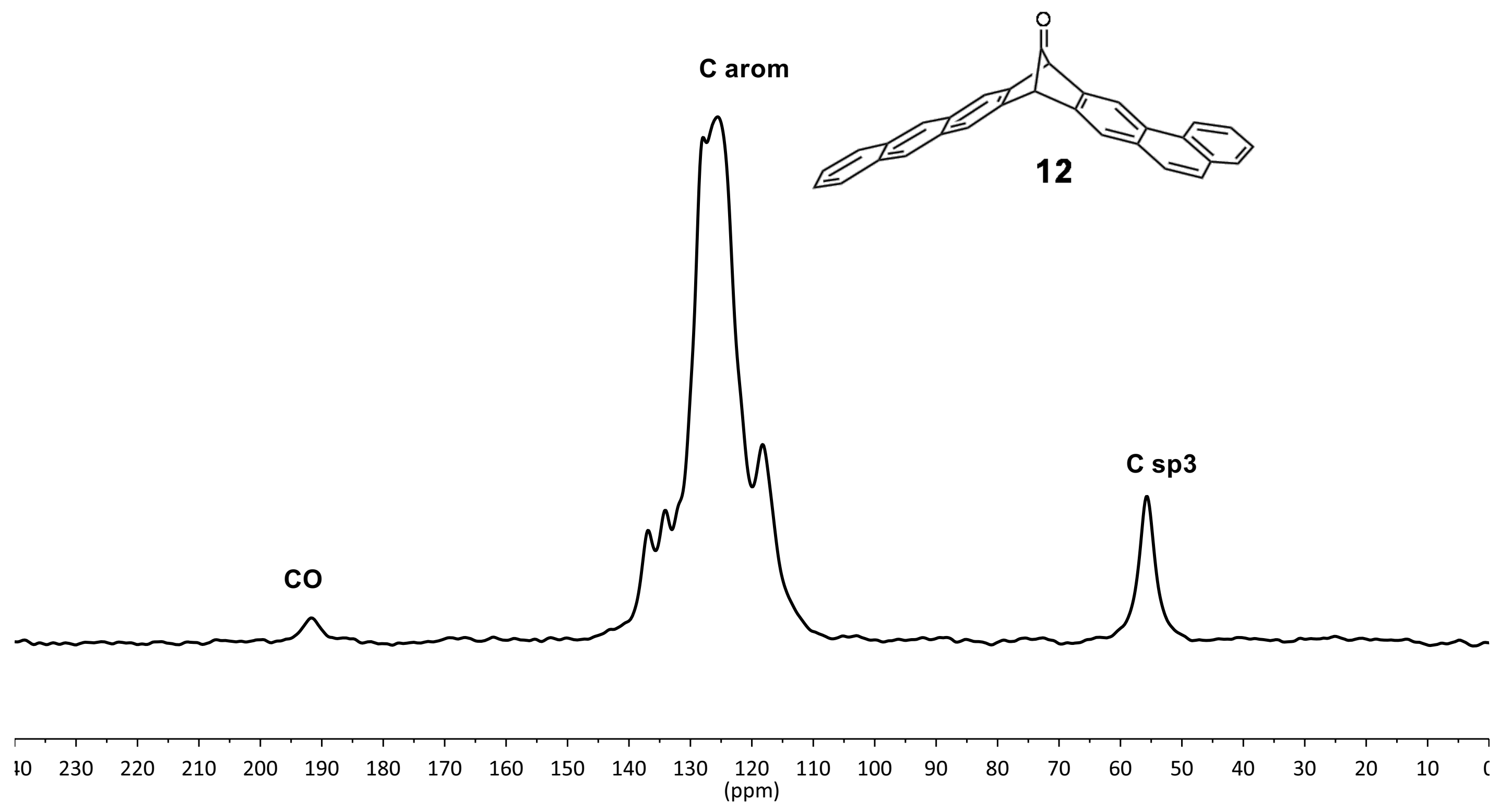


Sample: AJ174 ? - heated Probe: $2.5 \mathrm{Vr}=14 \mathrm{kHz}$ 13C CP MAS

\section{C arom}

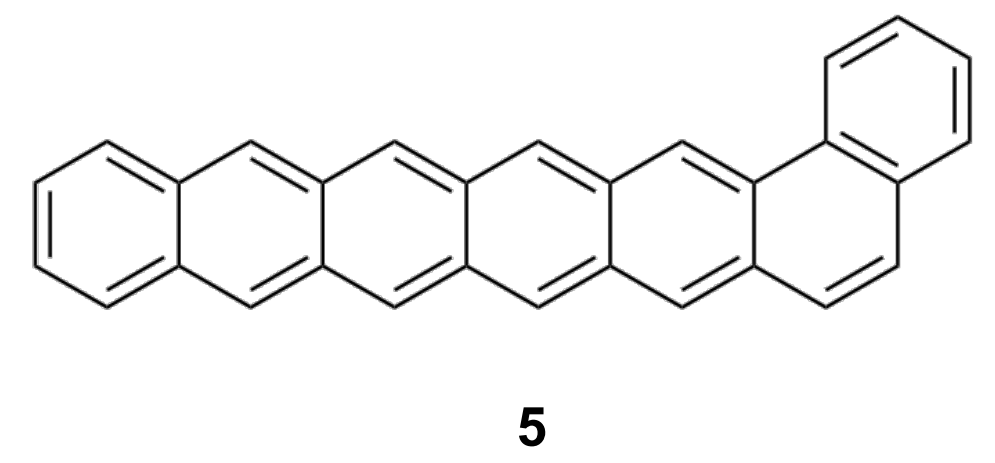


Infrared spectra of acenes and precursors (KBr pellets)

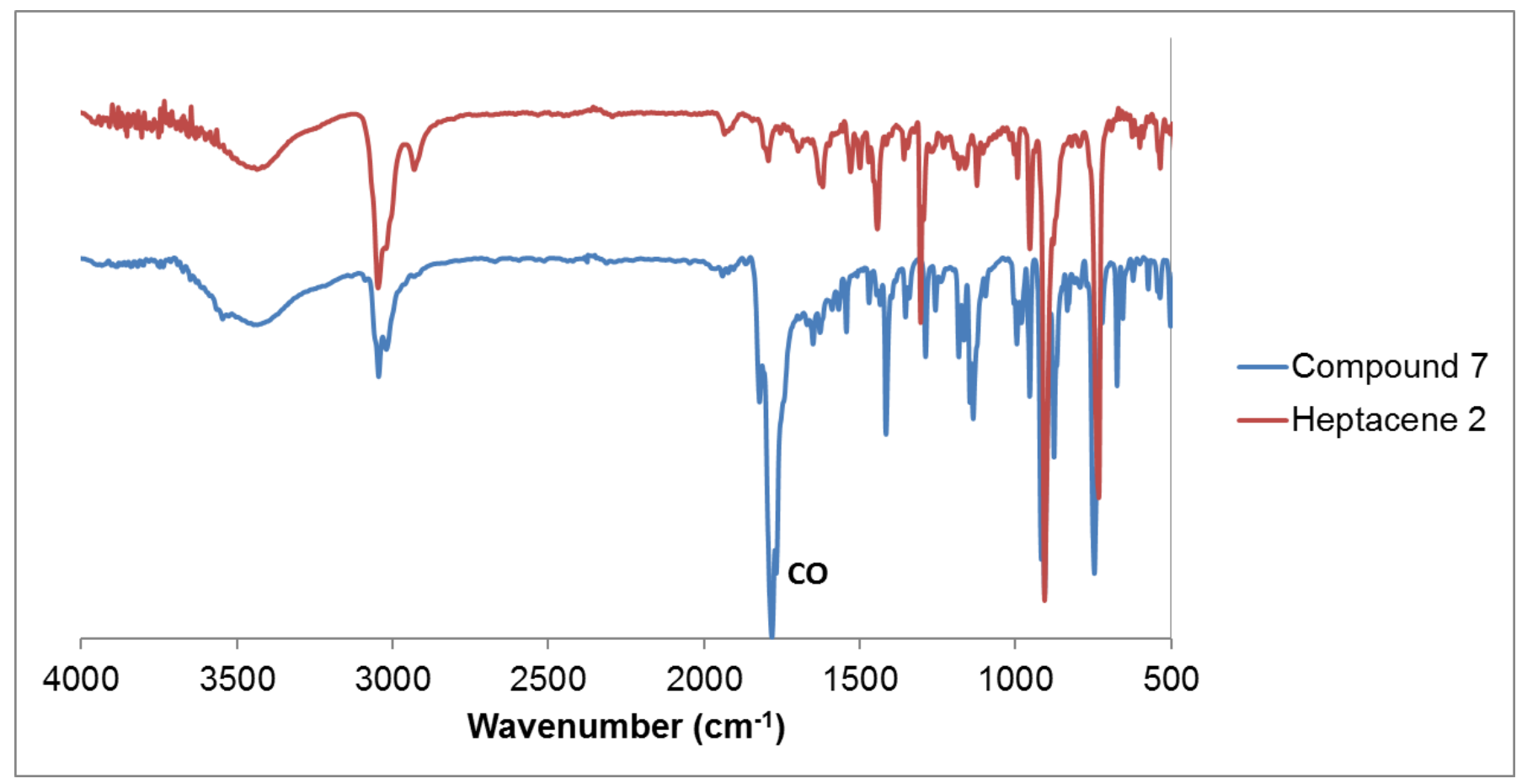

Infrared spectra of heptacene 2 and its precursor 7.

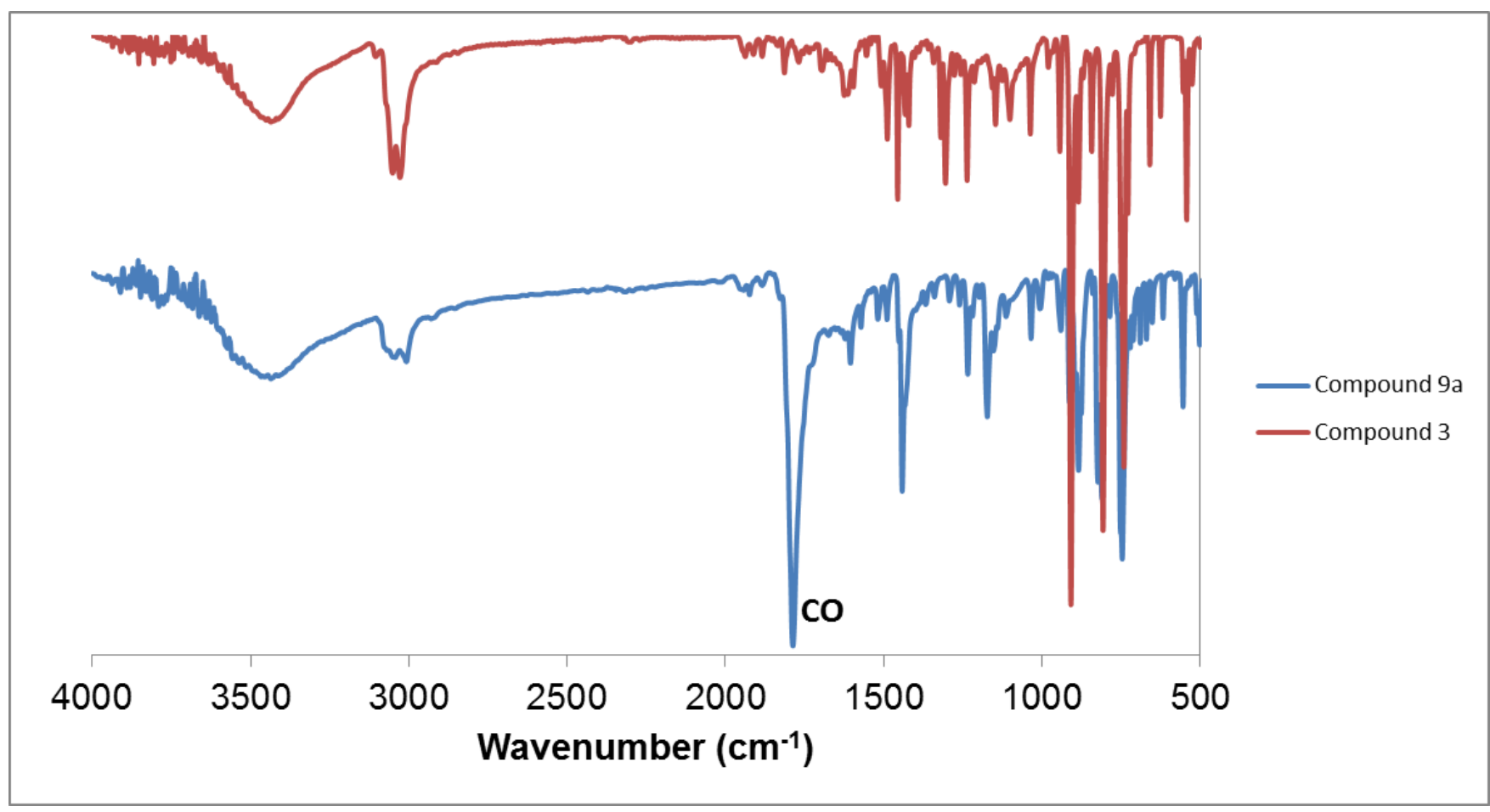

Infrared spectra of trans-DBPen 3 and its precursor 9a. 


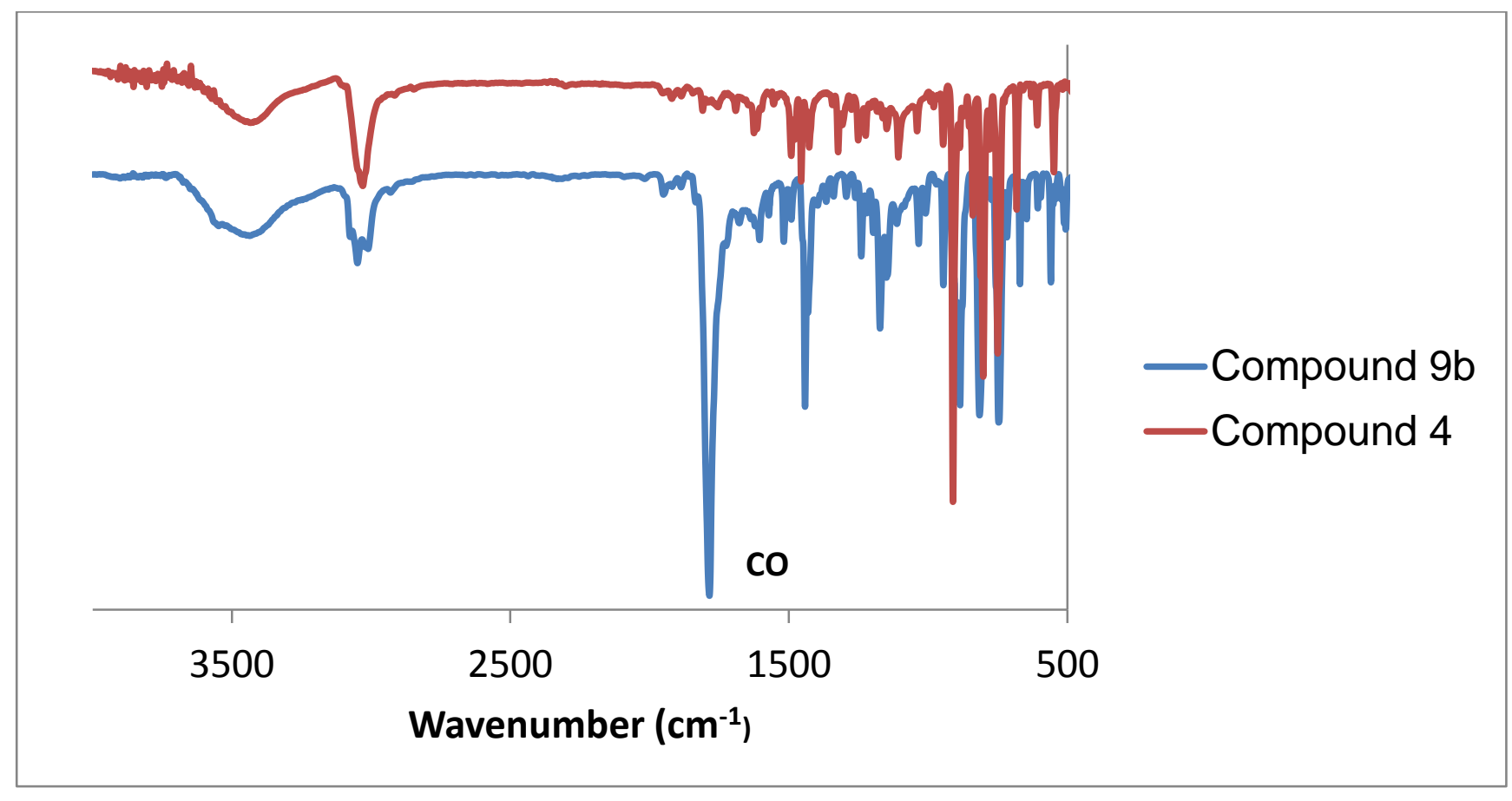

Infrared spectra of $c i s-D B P e n ~ 4$ and its precursor $9 \mathrm{~b}$.

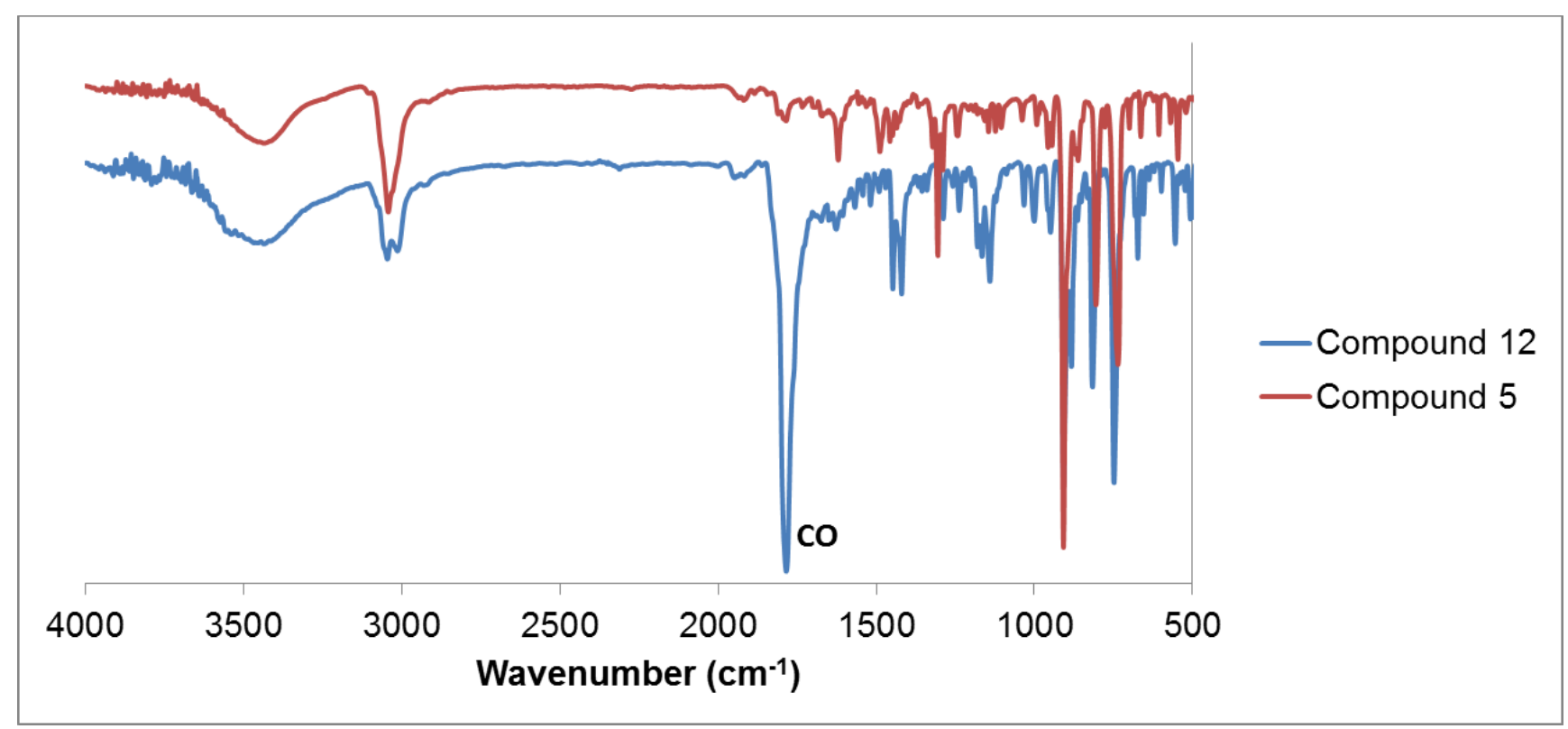

Infrared spectra of benzohexacene 5 and its precursor 12 . 
Thermal Gravimetric Analysis of compounds 9b/3, 9a/4, and 12/5 showing the decarbonylation temperatures.

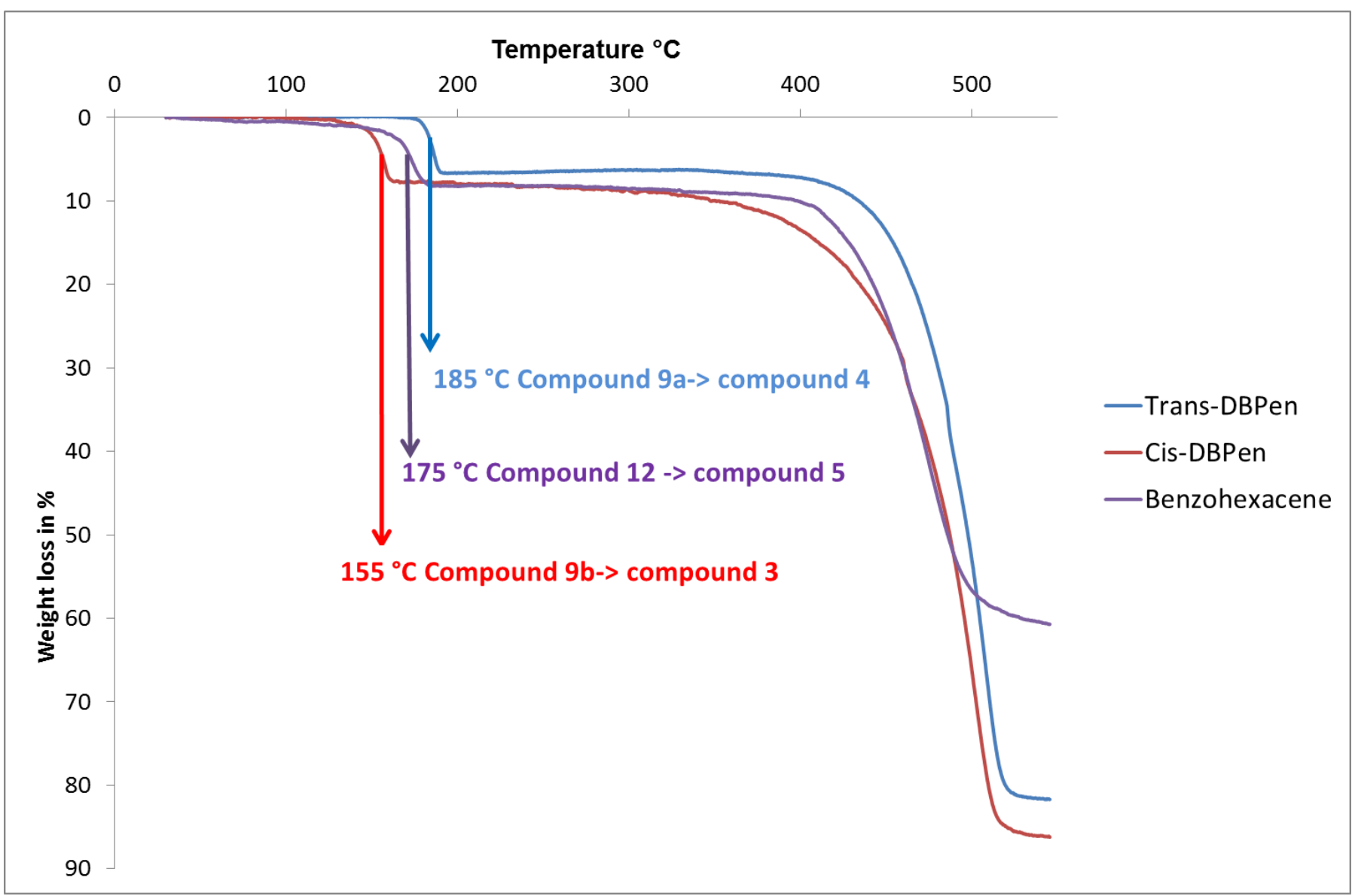




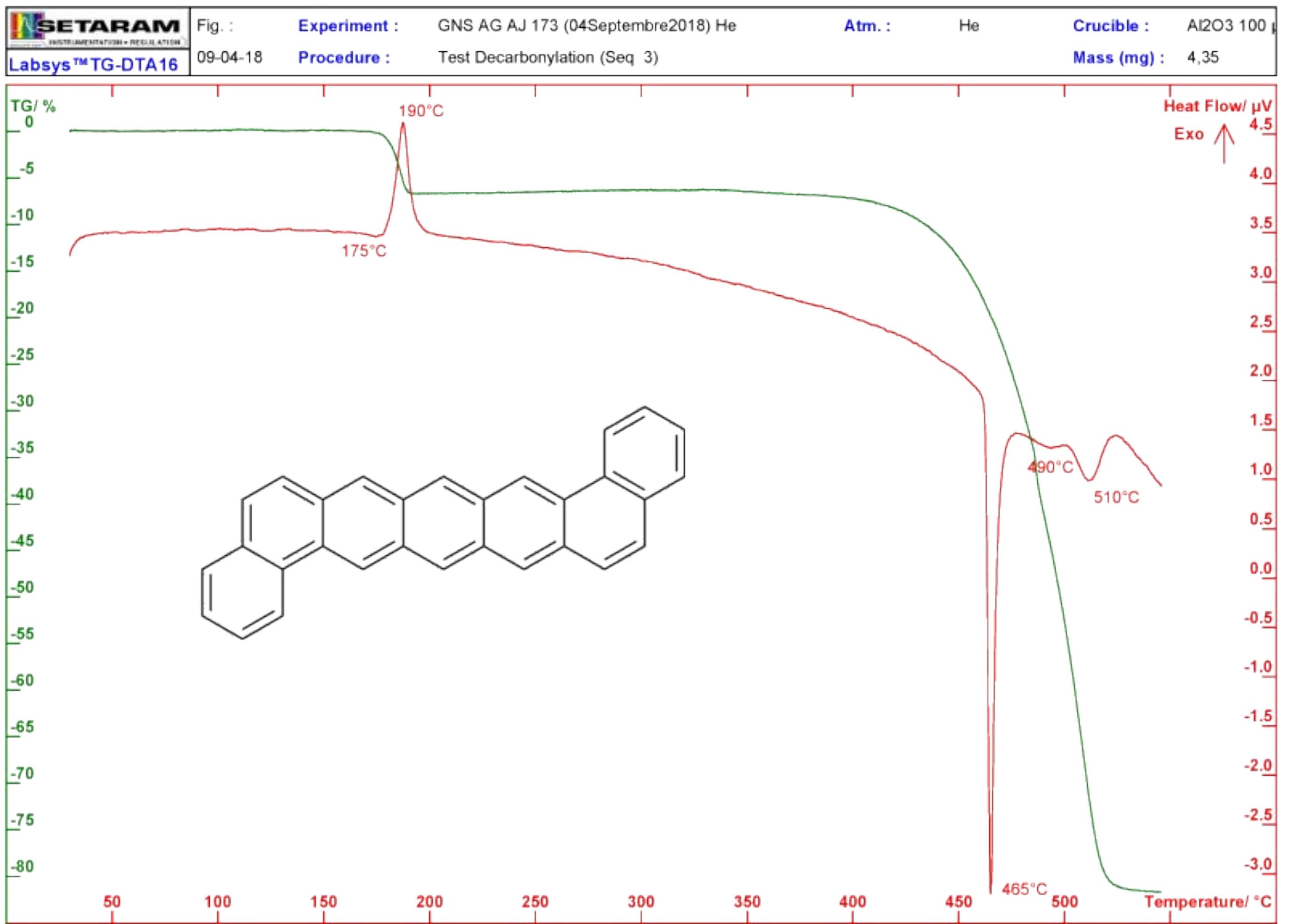




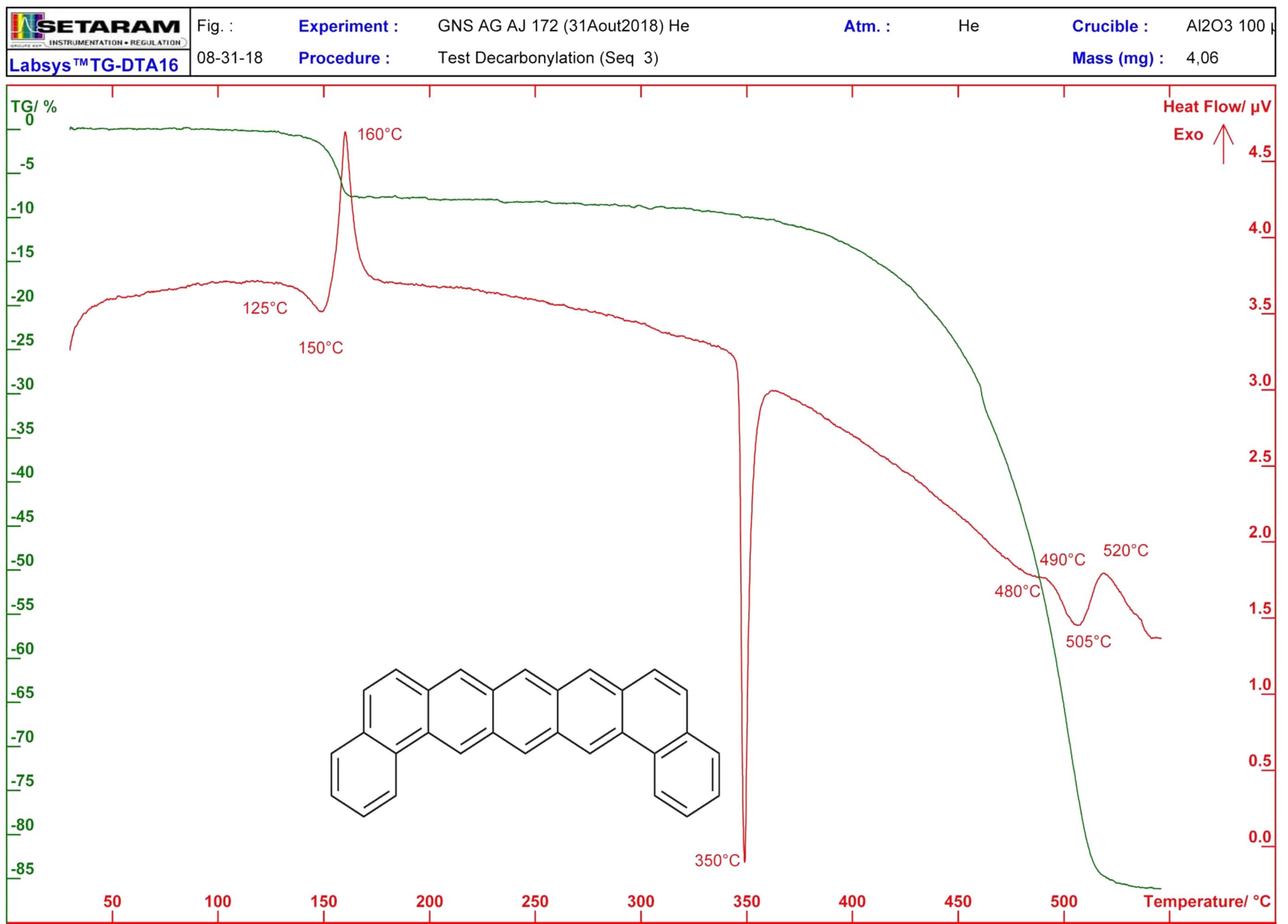

